"This document is the Accepted Manuscript version of a Published Work that appeared in final form in Accounts of Chemical Research, copyright (c) American Chemical Society after peer review and technical editing by the publisher. To access the final edited and published work see https://pubs.acs.org/doi/abs/10.1021/acs.accounts.8b00137?src=recsys\&journalCode=achre4 "

\title{
Promoting Intermolecular C-N Bond Formation under the Auspices of Iodine(III)
}

\author{
Kilian Muñiz \\ Institute for Chemical Research of Catalonia (ICIQ) \\ The Barcelona Institute of Science \\ Av. Països Catalans 16, 43007 Tarragona, Spain \\ kmuniz@iciq.es \\ ICREA \\ Passeig Lluís Companys, 23, 08010 Barcelona, Spain
}

\section{CONSPECTUS}

The quest for the development of new protocols that provide general conditions for oxidative carbon-nitrogen bond formation has grown over recent years. Within this context, due to practicability considerations and benigness aspects in biochemical sciences, reactions that rely on main group oxidants as the only promoters have received particular interest. We have recently found that simple protonolysis events enable the incorporation of nitrogenated groups of the bissulfonimide family into the coordination sphere of common iodine(III) complexes such as diacetoxy iodobenzene. The products of the type $\operatorname{ArI}(\mathrm{OAc})\left(\mathrm{NT}_{2}\right)$ represent rare examples of iodine(III) compounds displaying reactive iodine-nitrogen single bonds. Further protonolysis furnishes the corresponding iodine(III) compounds $\operatorname{ArI}\left(\mathrm{NTs}_{2}\right)_{2}$ containing two defined iodine-nitrogen single bonds for unprecedented dual transfer of both nitrogenated groups. It is of great synthetic importance that these new compounds contain iodine-nitrogen entities, which upon dissociation in solution lead to electrophilic iodine centers and nucleophilic nitrogen groups. This has enabled the development of a body of conceptually new amination reactions, which do not rely on conventional electrophilic nitrogen reagents, but rather employ the iodine(III) as an electrophilic activator and the bissulfonimides as the source of subsequent nucleophilic amination. Additional diversification arises from the ambident nature of bissulfonimines enabling oxygenation pathways. The exciting chemistry covered in this account comprises structural features of the reagents (including X-ray analysis), scope and limitation in synthetic amination of different hydrocarbons (including $\mathrm{sp}-, \mathrm{sp}^{2}$ - and $\mathrm{sp}^{3}$-hybridized centers as in acetylenes, alkenes, enols, butadienes, allenes, arenes and alkylketones) and physical-organic and theoretical analysis of the underlying reaction mechanisms. The oxidative transformations with all their rich diversifications originate from the versatile redox chemistry of the iodine(III) and iodine(I) pair, which shares several aspects of transition metal high oxidation state chemistry. For the present aryliodine(III) reagents, steric and electronic fine-tuning is possible through accurate engineering of the arene substituent. In addition to the general reactivity of the I-N bond, chiral aryliodine(III) 
reagents with defined stereochemical information in the aryl backbone are conceptually compatible with this approach. Thus, the development of enantioselective amination reactions with up to $99 \%$ ee was also successful. Several of the active enantioselective reagents have been isolated and structurally characterized. Following this approach for the important class of chiral vicinal diamines, an unprecedented direct diamination of alkenes could be conducted in an enantioselective catalytic manner under full intermolecular reaction control. This latter reaction is based on the precise engineering of a chiral aryliodine(III) catalyst in combination with bismesylimide as nitrogen source. It is the consequence of the precise understanding of the reaction behavior of structurally defined bisimidoiodine(III) reagents.

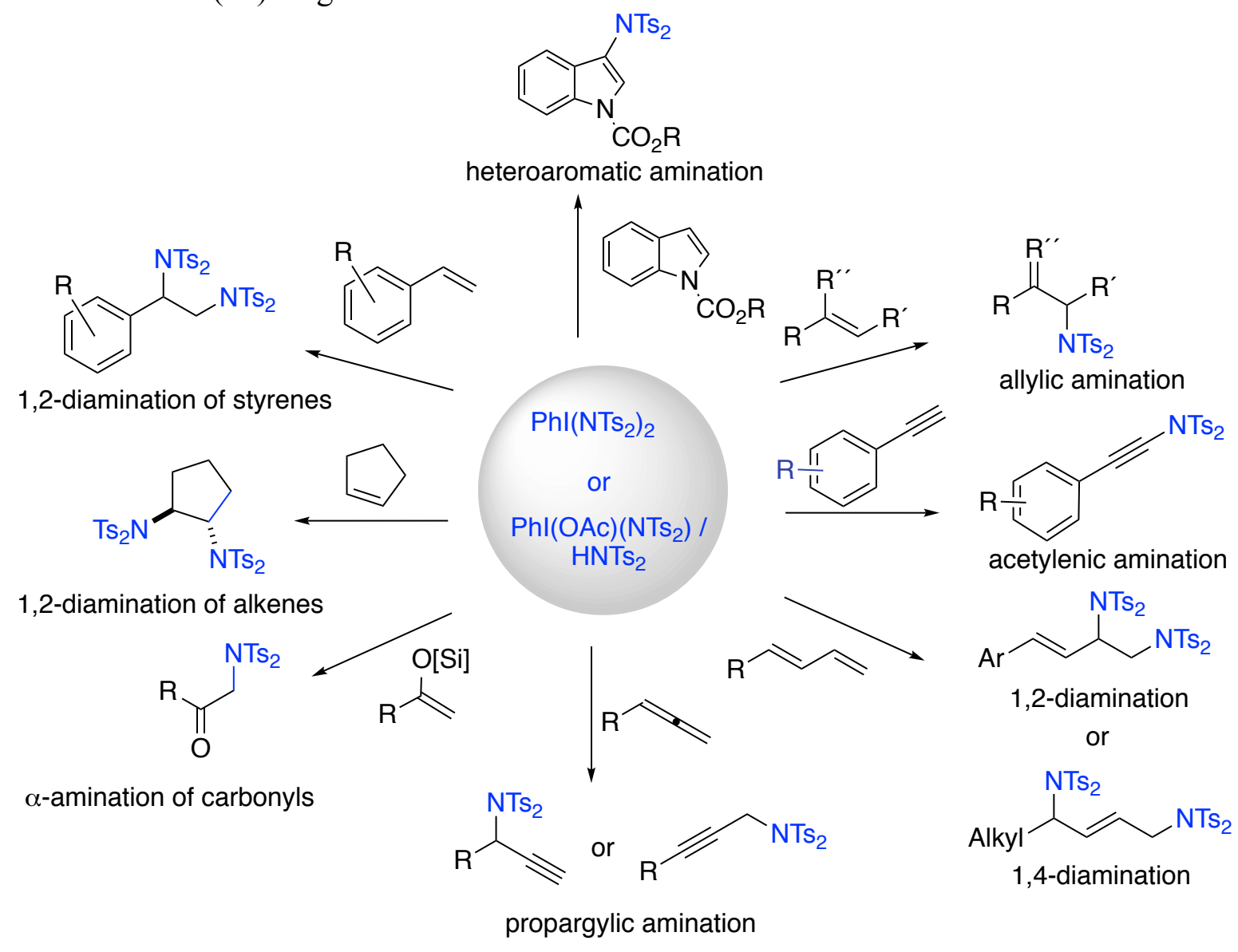

\section{INTRODUCTION}

The direct amination of hydrocarbon atoms represents the Holy Grail in amination chemistry. Unlike many other synthetic organic transformations, it has no biochemical precedence and thus requires elaboration of innovative protocols. Polyvalent iodine(III) reagents have emerged as a useful tool in oxidation chemistry, ${ }^{1-3}$ and among many other accomplishments have also enabled the development of new amination chemistry. A decade ago, the state of the art in the field was based on bis(trifluoroacetoxy)iodobenzene, $\mathrm{PhI}\left(\mathrm{O}_{2} \mathrm{CCF}_{3}\right)_{2}$ (PIFA). Upon interaction with $\mathrm{NH}$ groups from amines, amides, imines and related compounds, this reagent forms $\mathrm{N}$-iodinated intermediates of the general structure $\mathbf{A}$, 
which subsequently undergo heterolytic cleavage to provide electrophilic nitrogen. ${ }^{4,5}$ Subsequent chemical transformations then derive from the presence of suitable electronrich groups to initiate $\mathrm{C}-\mathrm{N}$ bond formation (Figure 1).

An isolated imido bromine(III) reagent further illustrated the electrophilicity of such nitrogen centers. Nucleophiles readily attack at the $\mathrm{N}-\mathrm{Br}-\sigma *$-orbital within a scenario B even promoting direct $\mathrm{C}-\mathrm{H}$ amination of alkanes at room temperature. ${ }^{6,7}$

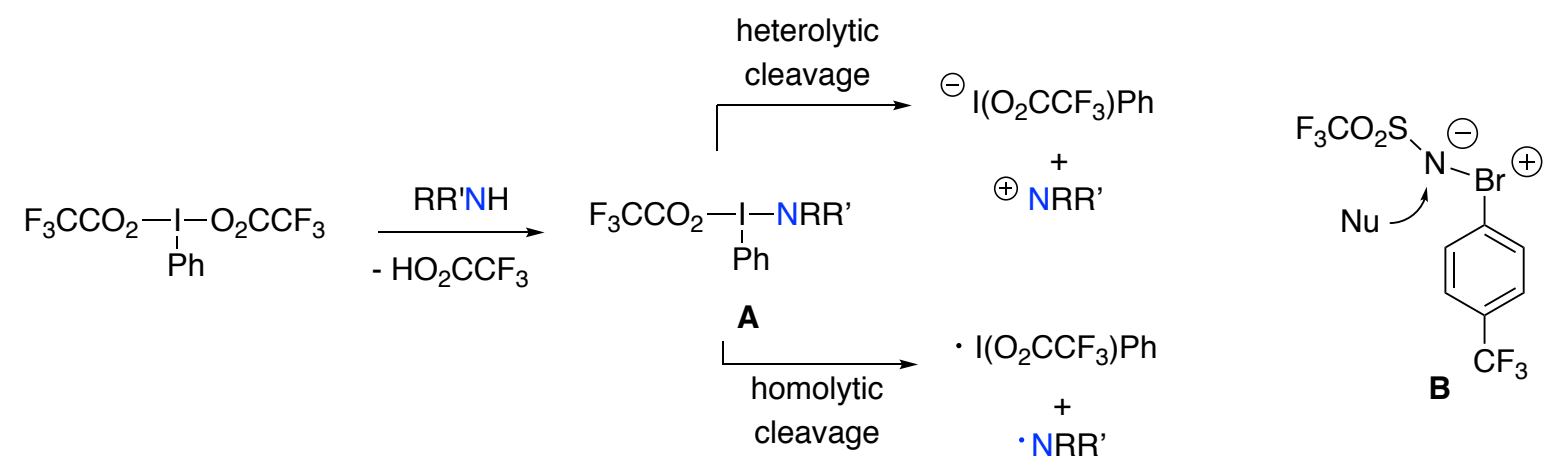

Figure 1. Classic reactions from aminated high oxidation state halides.

An attractive conceptual alternative would rest with the opposite behavior in which an electrophilic iodine(III) initiates the oxidative functionalization at carbon followed by nucleophilic amination. Such a pathway would be reminiscent of the established nucleophilic amination chemistry and certainly follow the intuitive paths for $\mathrm{C}-\mathrm{N}$ bond synthesis. It would furthermore promote the classical nature of iodine(III) reagents as electrophilic oxidants. ${ }^{1-3}$

Based on their prominent role in earlier work on iodine(III)-promoted high oxidation state palladium catalysis, ${ }^{8-13}$ bissulfonimides were identified as suitable nitrogen sources. Due to two sulfonyl substituents, the central nitrogen displays pronounced $\mathrm{sp}^{2}$-character resulting in an acidified N-H bond. As a result, bissulfonimides react cleanly and irreversibly with several preformed iodine(III) compounds through protonolysis. The resulting structural chemistry of the iodine(III) complexes incorporating bissulfonimides is very rich. It was explored in detail for bistosylimide as the representative amino component.

\section{DISCUSSION}

Reagent synthesis. A rich structural chemistry arises from treatment of classic bis(acetoxy)iodobenzene PIDA 1 with bissulfonimide (Scheme 1). Upon stoichiometric reagent combination, formation of the mixed derivative $\mathrm{PhI}(\mathrm{OAc})\left(\mathrm{NTs}_{2}\right) \mathbf{2}$ is observed. ${ }^{14}$ This reaction is based on the higher acidity of bistosylimide over acetic acid and thus relies on an irreversible protonolysis event. As judged by in situ IR spectroscopy, the reaction is quantitative within minutes at room temperature. When the protonolysis proceeds in the presence of water traces, partial hydrolysis provides the $\mu$-oxo-bridged dimeric iodine(III) 3 with preserved iodine-nitrogen bonds. The same compound can be accessed directly from 1 through iminolysis in the presence of water. The basic $\mu$-oxo group in compound $\mathbf{3}$ is a good starting point for further structural diversification with protic reagents. It serves as 
precursor to iodine(III) reagents incorporating two different anions. More importantly, an additional protonolysis with $\mathrm{HNTs}_{2}$ gives expeditious access to the homoleptic iodine(III) reagent 4 incorporating two bisimido groups. ${ }^{15}$ The same compound can be obtained directly from PIDA or the parent mixed reagent $\mathbf{2}$ upon acetate exchange with bistosylimide under slightly more forcing conditions. Related compounds of 2-4 can be obtained from the corresponding reactions with other bissulfonimides such as bismesylimide and mixed mesyltosylimide or nosyltosylimide, among others. ${ }^{15}$

It is interesting to compare this rich imido iodine(III) chemistry with the reminiscent initial steps in historic aryliodine(III) diversification, which had been widely dominated by anion exchange reactions. ${ }^{1,16}$ The representative imido iodine(III) derivatives $\mathbf{2 - 4}$ from Scheme 1 can be considered the missing link regarding iodine(III) diversification.
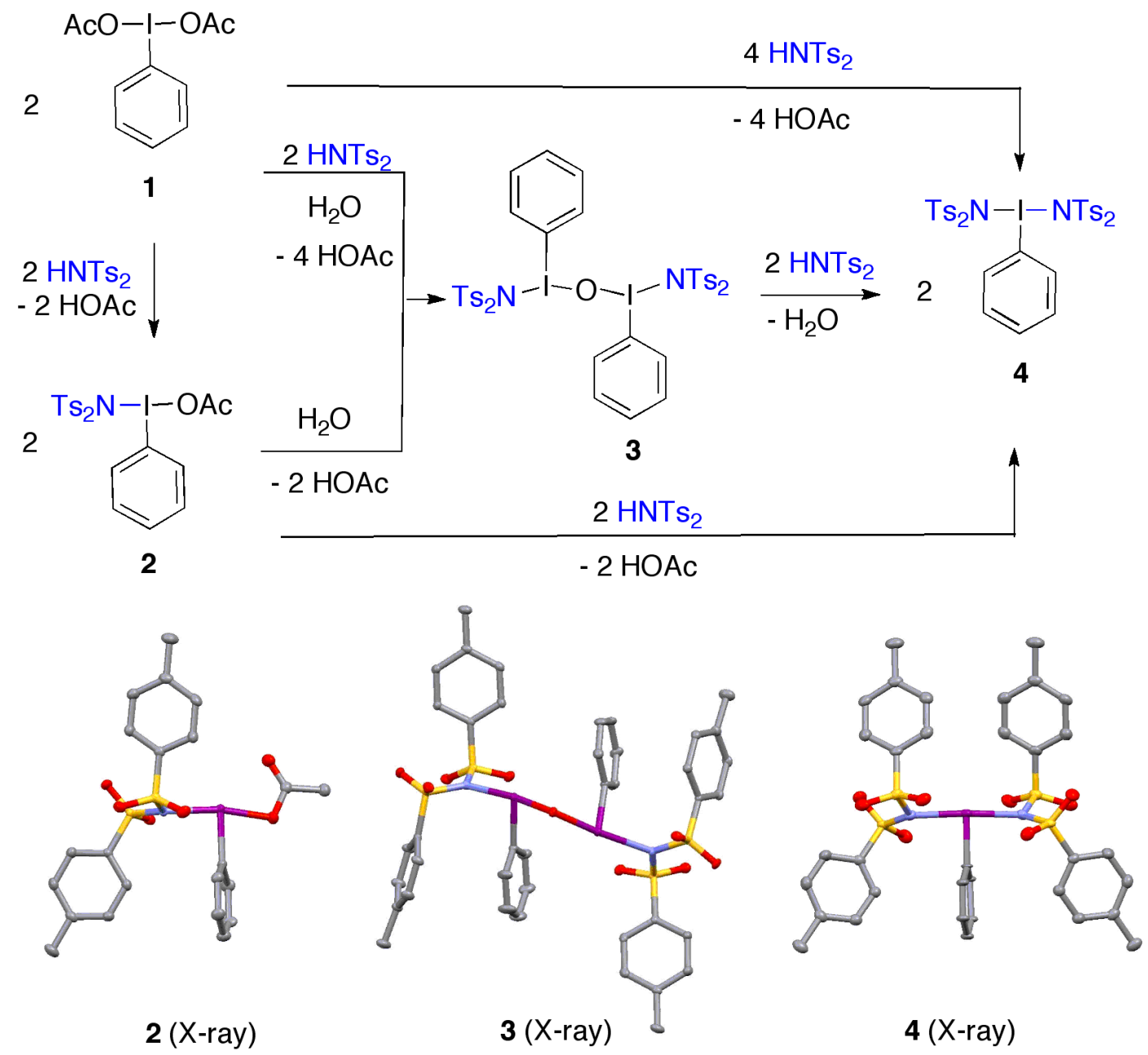
Scheme 1. Structural diversification of iodine(III) reagents incorporating bistosylimide.

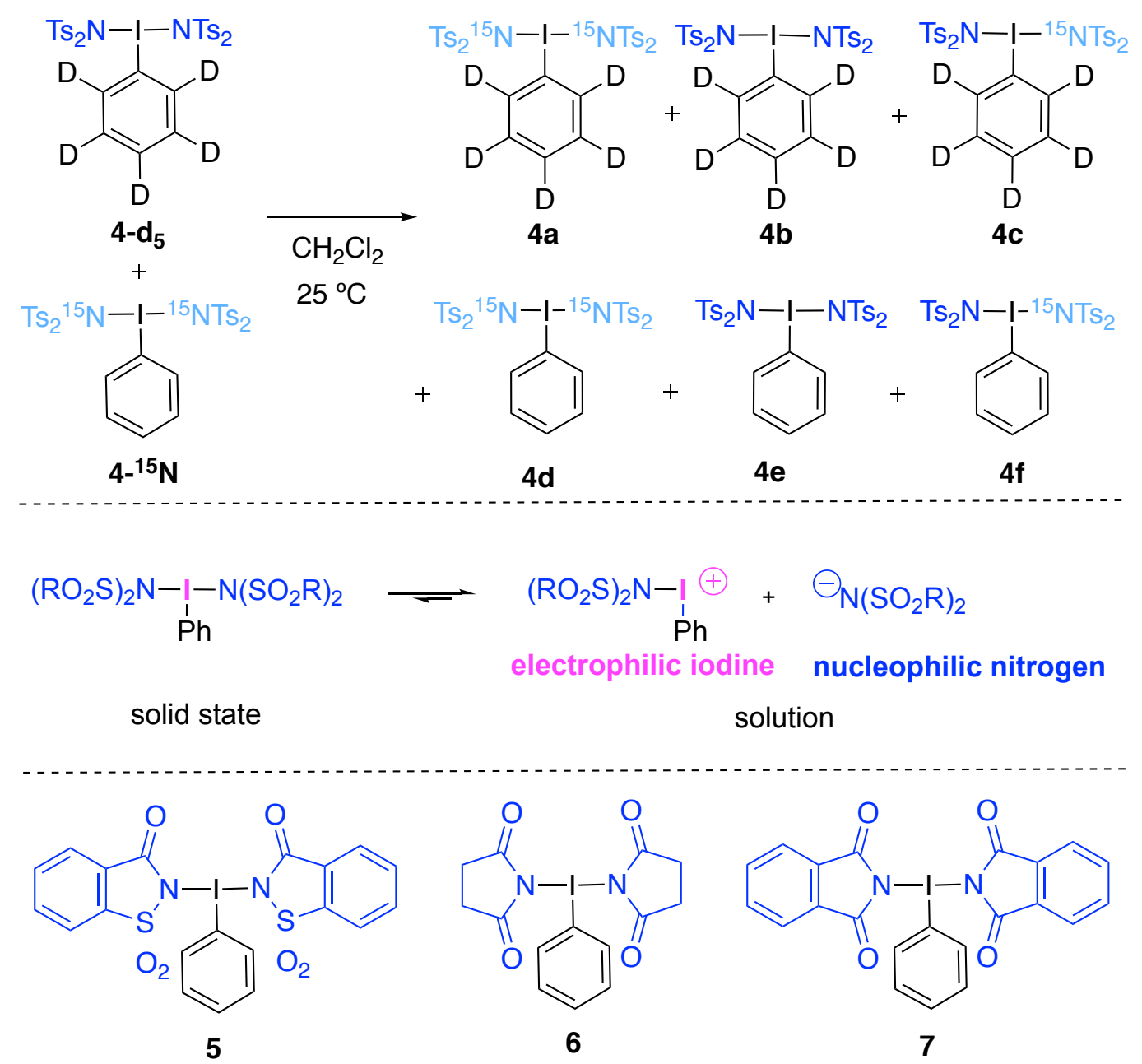

Scheme 2. Solution behavior of bisimidoiodine(III) compounds 4 and non-related compounds 5-7.

The solution behavior of bisimido iodine reagent 4 was found to be dominated by dissociation events based on the labile nature of the iodine-nitrogen single bond. Ultimately, this results in a dynamic behavior of these compounds. To illustrate this context, isotopically labeled derivatives $\mathbf{4 - 1 5}^{\mathbf{1 5}} \mathbf{N}$ with a ${ }^{15} \mathrm{~N}$-labeled bistosylimide and with pentadeuterated phenyl substituent $4-\mathbf{d}_{5}$ were prepared. At room temperature, their solution mixture sees a rapid complete statistic equilibration of nitrogen groups at the iodine centers generating all six possible isomeric derivatives 4a-f (Scheme 2). This was further evidenced by $\mathrm{MS}$ experimentation detecting all four cationic iodine fragments $\left[\mathrm{PhINTs}_{2}\right]^{+}$, $\left[\mathrm{PhI}^{15} \mathrm{NTs}_{2}\right]^{+},\left[\mathrm{C}_{6} \mathrm{D}_{5} \mathrm{INTs}_{2}\right]^{+}$and $\left[\mathrm{C}_{6} \mathrm{D}_{5} \mathrm{I}^{15} \mathrm{NTs}_{2}\right]^{+}$.

This observation is a pronounced difference to previously reported reagents of the type $\operatorname{ArI}[\mathrm{N}]_{2}$ such as bis(saccharin)iodobenzene (5), bis(succinimido)iodobenzene (6), and bis(phthalimido)iodobenzene (7). ${ }^{17-19}$ These compounds display a significantly stronger 
iodine-nitrogen bond and usually only react with strong nucleophiles. In particular, the iodine-phthalimido bond as in 7 has been invoked to serve as a precursor to nitrogen radicals $^{20}$ or electrophilic nitrogen sources ${ }^{4,5}$ depending on the reaction conditions. ${ }^{21,22}$ Defined nucleophilic behavior of phthalimide required the design of more advanced iodine(III) reagents, which still remain restricted to electron-rich organic substrates. ${ }^{23}$

Consequential of the discussed dissociative lability of the nitrogen-iodine bond, bisimido iodine reagent 4 is characterized by an enhanced electrophilicity at the iodine(III) center, which should accelerate interaction with the $\pi$-system of organic substrates. ${ }^{15,24} \mathrm{~A}$ broad reactivity pattern of compounds $\mathbf{2 - 4}$ should thus be obtainable when exposing them to unsaturated organic functionalities.

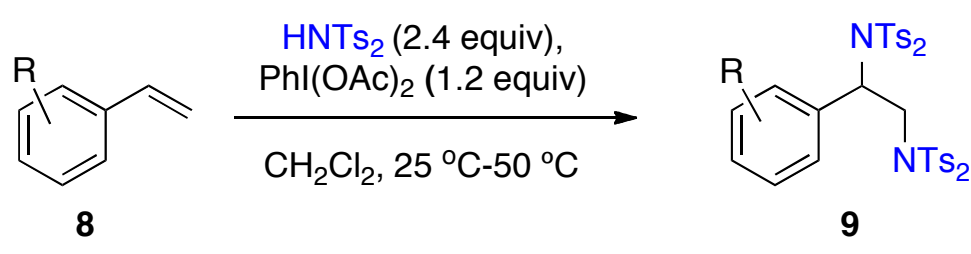

11 examples, $40-88 \%$
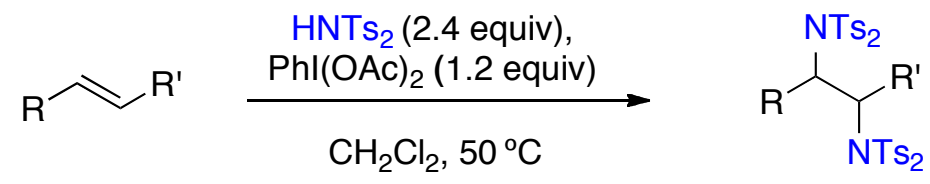

10

11

14 examples, $47-80 \%$

Scheme 3. Iodine(III)-promoted vicinal diamination of alkenes.

Amination of unsaturated $\mathbf{C}-\mathbf{C}$ bonds. At the outset, the reactivity between alkenes and bisimidoiodine reagents was explored. ${ }^{25}$ It was expected that reagents 2-4 should exercise as effective oxidants for vicinal difunctionalization as established for the parent halogenation and oxygenation reactions. ${ }^{24} \mathrm{In}$ fact, the $\mathrm{PhI}(\mathrm{OAc})_{2} / \mathrm{HNTs}_{2}$ and $\mathrm{PhI}(\mathrm{OAc})_{2} / \mathrm{HNMs}_{2}$ reagent combination displays an unprecedented substrate scope in the vicinal diamination of alkenes. It comprises a total of 62 different alkenes including different alkene geometries, diverse electronics and high functional group tolerance. Although the active bisimidoiodine(III) reagents were generated in situ, the imido nucleophiles were dominant in the alkene difunctionalization and the potentially competing oxygenation was never observed. Yields commonly do not experience big changes between reactions with preformed reagents or with in situ reagent formation. The observed chemical behavior was probed against styrenes 8 the privileged substrate class. As expected, clean diamination reactions towards 9 were observed, and the new diamination could be extended successfully to diamination of terminal and internal aliphatic alkenes $\mathbf{1 0}$ as well (Scheme 3).

To further explore the mechanistic background, the performance of a series of bisimido iodine(III) reagents 4-X with different 4-substituted arene backbone in the diamination of 4-fluorostyrene 8a was explored. ${ }^{26}$ They demonstrate a significant dependence of the reaction rate on the relative electron-density of the iodine(III) center (Scheme 4). The 
higher the latter, the faster the diamination proceeds. Based on these observations the decisive step in the diamination of alkenes with bistosylimide as nitrogen source was proposed to consist of the dissociative pre-equilibrium discussed in Scheme 2 for parent 4. The obtained data evidences acceleration with the 4-methyl substituent based on an electronic donor stabilization of the involved cationic intermediate 4'. The relation between electron density and overall rate requires accurate balance in a way that electronic stabilization does not reduce the electrophilicity at iodine too strongly as observed for the 4-methoxy substituent.

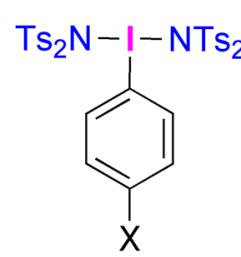

4-X $\left(\mathrm{X}=\mathrm{CF}_{3}, \mathrm{Cl}\right.$, $\mathrm{H}, \mathrm{CH}_{3}, \mathrm{OCH}_{3}$ )

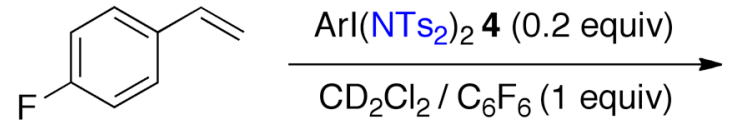

8a

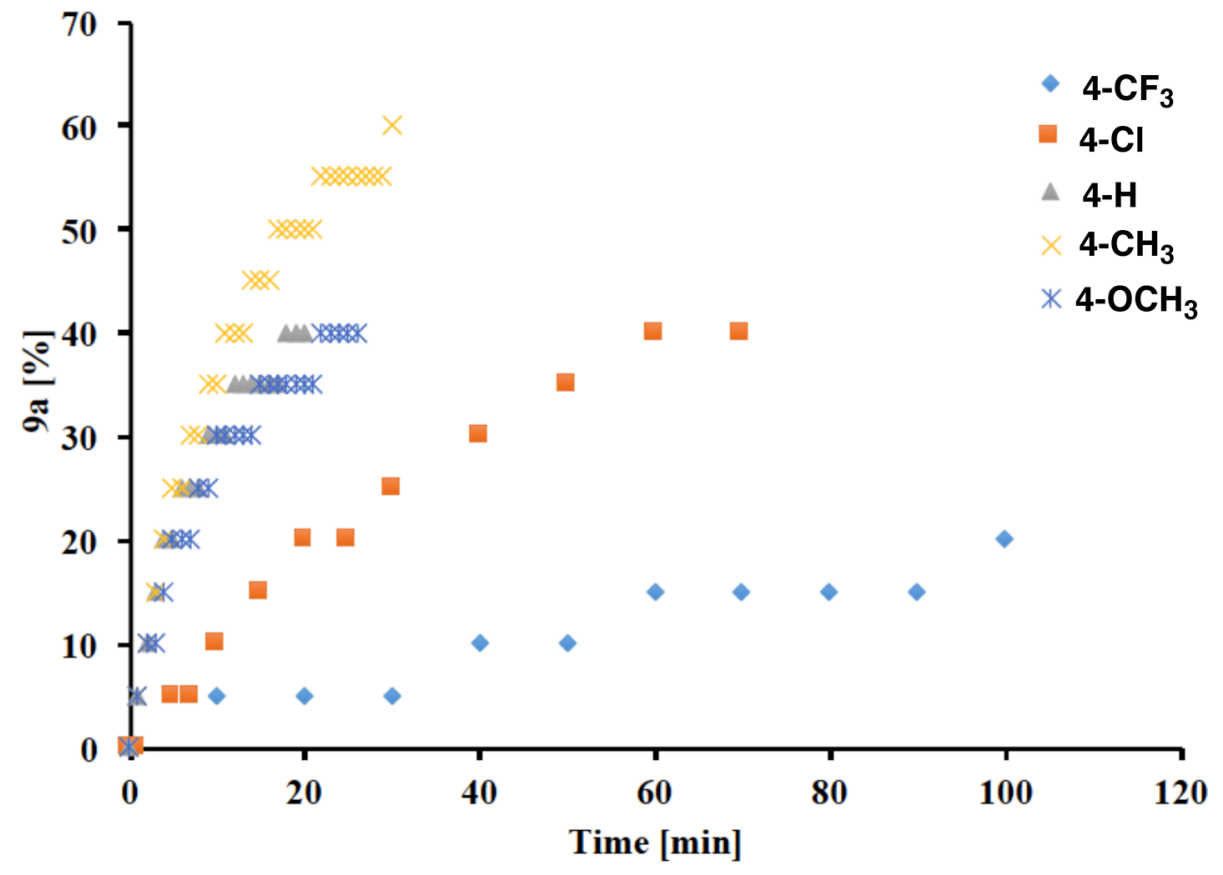


Scheme 4. Electronic effects on iodine(III) reagents in the diamination of 4-fluorostyrene

8a. Further mechanistic insight was obtained from computational chemistry. ${ }^{27}$ DFT analysis of the course of reaction between styrene and bis(dimesylimido)phenyliodide confirmed the expected initial coordination of styrene to the cationic iodine(III) reagent $\mathrm{PhI}\left(\mathrm{NMs}_{2}\right)_{2}$, but revealed a surprising subsequent nucleophilic addition of the dimesylimido anion (Scheme 5). The latter occurs through $\mathbf{C}$ with the nucleophilic mesomeric oxygen atom of one of the mesyl substituents and not through the expected nitrogen atom. As a result, benzylic oxygenation $\mathbf{D}$ is observed. The remaining nucleophilic nitrogen is then recovered for an intramolecular displacement of the iodine(III) leaving group to form the dioxooxathiazolidinium intermediate $\mathbf{E}$. The reductive displacement of phenyliodine generates a second bismesylimido nucleophile, which opens the cationic intermediate $\mathbf{E}$ at its activated benzylic position and thereby directly generates the vicinal diamine product 9b. The privileged performance of styrenes in diamination may thus be the result of their preferential provision of benzylic positions. To the best of our knowledge the observed ambident behavior of bismesylimide in the oxidative diamination is unprecedented in bissulfonimide chemistry.

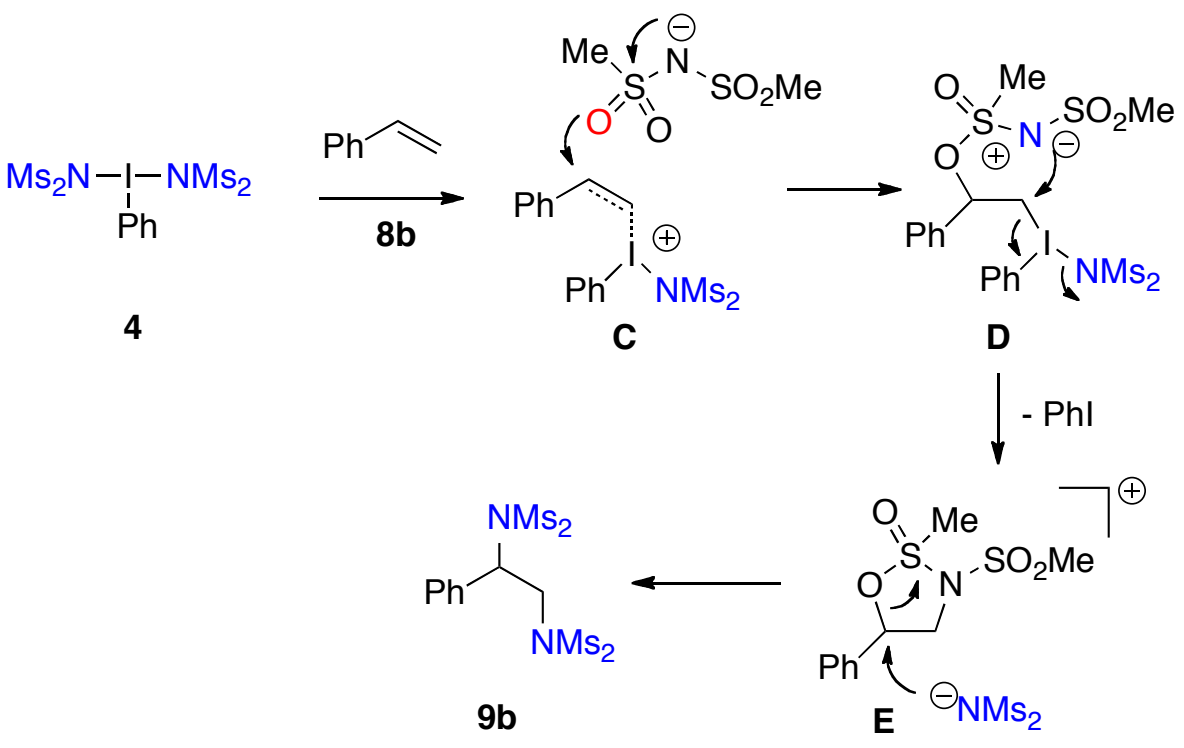


Scheme 5. Calculated major intermediates along the diamination pathway.

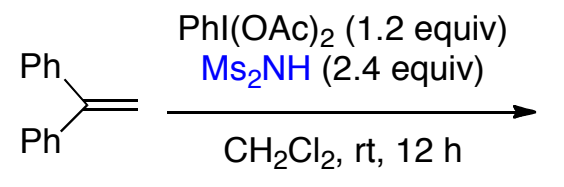

12

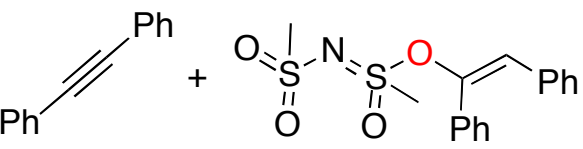

$13(40 \%)$
$14(25 \%)$

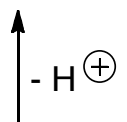

G

Scheme 6. Demonstration of ambident nature for bismesylimide.

To gain unambiguous support for the ambident nature of bissulfonimides, oxidation of 1,1diphenyl ethylene 12 was investigated, which generated a mixture of tolane (13) and the enol derivative 14 (Scheme 6). The latter offers the elusive experimental proof for C-O bond formation with bismesylimide. It is explained by an initial alkene coordination to iodine(III) and subsequent oxygenation with ambident $\mathrm{Ms}_{2} \mathrm{NH}$ to benzylic oxygenation product $\mathbf{F}$. Reductive elimination of iodine(III) induces a pinacol-type 1,2-phenyl shift to $\mathbf{G}$, from which 14 forms upon elimination. Tolane (13) forms from 14 via a thermal synelimination.

The aminating power of the bissulfonimide/iodine(III) system was further detailed by two additional reactions (Scheme 7). ${ }^{15}$ Aminated substrates 11a and 9c demonstrate that the potentially dominating intramolecular reactivity can be successfully overridden. Instead of the cyclization to the corresponding piperidine and indole heterocycles, selective vicinal diamination to 11a and 9c takes places. This is another unique aspect of the present iodine(III) reagents, since related oxygenated iodine(III) reagents promote the corresponding cyclization reactions. ${ }^{1,4,5}$ 


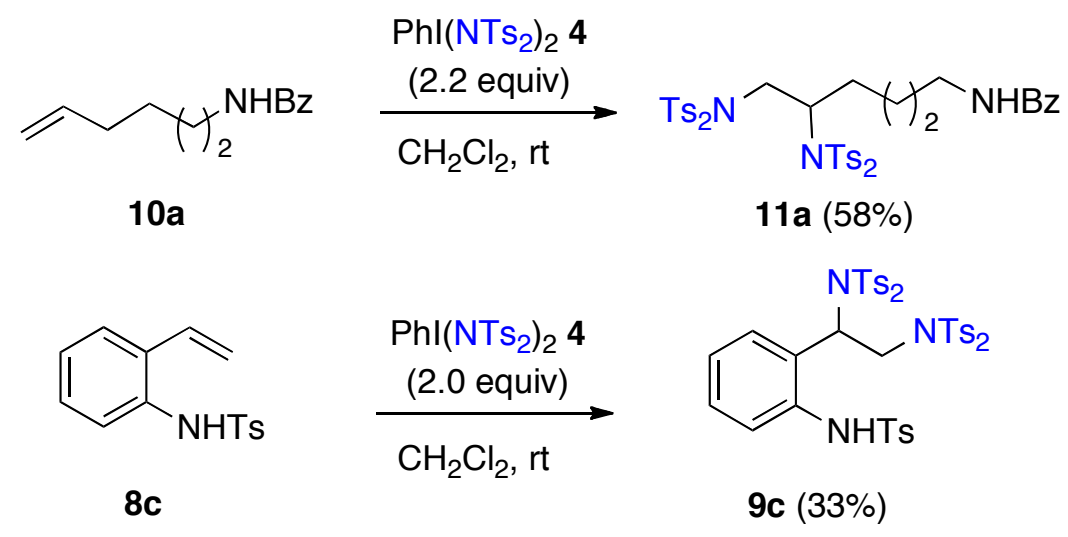

Scheme 7. Vicinal diamination of alkenes overriding competing cyclization reactions.

The structural features of the backbone of the iodine(III) reagent can be varied. For example, binary iodine reagents can be generated from the common biaryl motif. ${ }^{28}$ Oxidation of 2,2'-diiodobiphenyl and treatment with bistosylimide provides the $\mu$-oxobridged derivative $\mathbf{1 5}$ and reagent 16 with two independent bis(ditosylimido)iodo groups upon further aminolysis. Both reagents $\mathbf{1 6}$ as well as $\mathbf{1 5}$ in combination with two molecules of bistosylimide promote selective vicinal diamination reactions of alkene classes $\mathbf{8}$ and $\mathbf{1 0}$. Both iodine(III) groups are active for alkene oxidation and thus 0.6 equivalents of reagents are usually sufficient for diamination. Since after the first diamination is completed, the remaining iodine(III) experiences an altered electronic and steric environment, the bisimidoiodine(III) unit once again demonstrates a remarkable flexibility. In fact, reagent 15 itself is capable of promoting a stoichiometric diamination of styrene in $88 \%$ isolated yield. This outcome can be rationalized by a dynamic behavior of the two $\mu$-oxo-bridged iodine centers (Scheme 8). Upon dissociation of one bistosylimido moiety, opening of the $\mu$-oxo-bridge in $15^{\prime}$ provides an inactive iodosoarene moiety and a reactive bisimidoiodine(III) group in 15", which promotes the diamination reaction. 


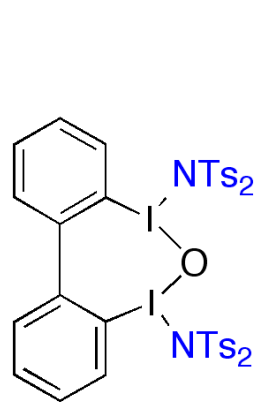

15

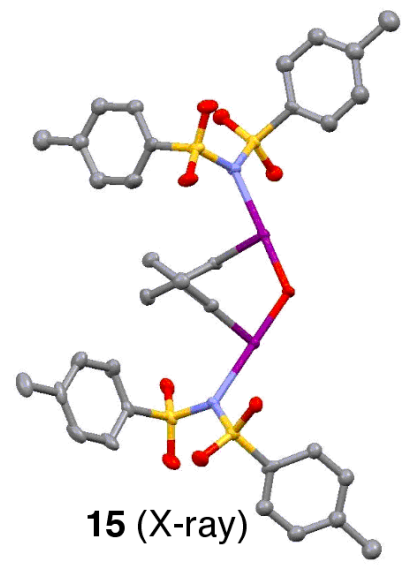

iodine(III) reagent<smiles>CC(C)[N+](C)(C)c1ccccc1-c1ccccc1-c1ccccc1</smiles>

16

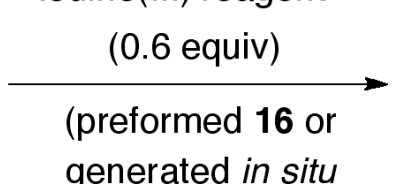
$\mathrm{R} \curvearrowright$
8,10
from $15+2$ HNTs $_{2}$ )<smiles></smiles>

$\mathbf{9 , 1 1}$

7 examples, 43-80\% yield

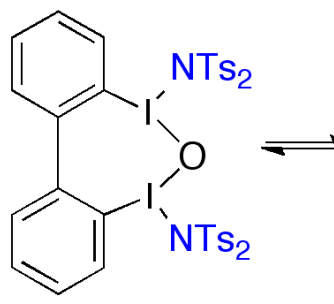

15

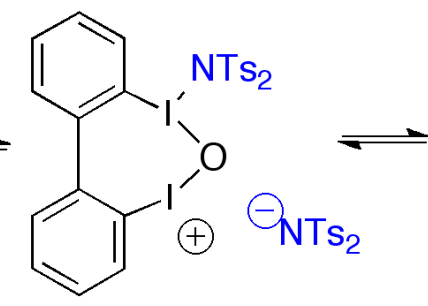

15<smiles>O=Ic1ccccc1-c1ccccc1[Al-][In-][Mg]</smiles>

$15 ”$

Scheme 8. Synthesis and dynamic behavior of diiodine(III) reagents and their application in diamination of styrenes.

The $\mathrm{PhI}(\mathrm{OAc})_{2} / 2 \mathrm{HNTs}_{2}$ reagent combination is also effective for an unprecedented monodiamination of conjugated dienes and trienes. ${ }^{29}$ Aryl-substituted 1,3-butadienes 17 give rise to selective vicinal diamination at the remote alkene (Scheme 9). The reaction outcome is identical for (E)- and (Z)-dienes, which suggests the involvement of an isomerizable intermediate such as an allylic cation. 1,4-Disubstituted 1,3-butadienes provide diastereomerically pure products. The observed product constitution $\mathbf{1 8}$ was rationalized by the higher stability of the remaining conjugated alkene as a styrene derivative. This selectivity can be reversed through the introduction of an ester substituent as in 19, which favors formation of the corresponding diamination product $\mathbf{2 0}$ with a remaining acrylate entity. For aliphatic substitution, isomeric mixtures are usually obtained, although 1,4diamination can be the predominant or exclusive pathway. For the 1,3,5-triene 21 a rare example of a selective 1,6-diamination ${ }^{30}$ to $\mathbf{2 2}$ was accomplished. 

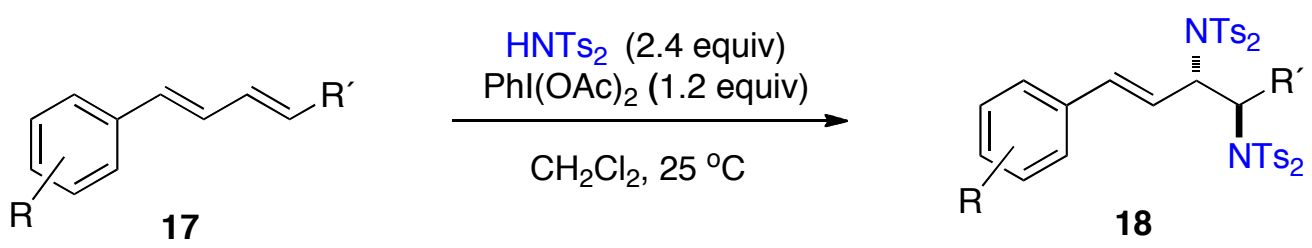

10 examples, $59-75 \%$

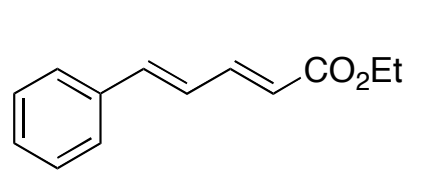

19
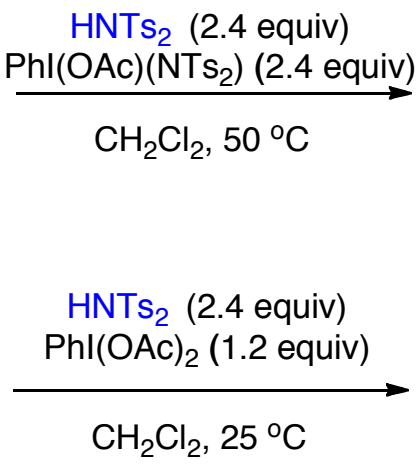<smiles>CCOC(=O)C=CC(C(c1ccccc1)[N+](=O)[O-])[N+](=O)[O-]</smiles>

$20(64 \%)$

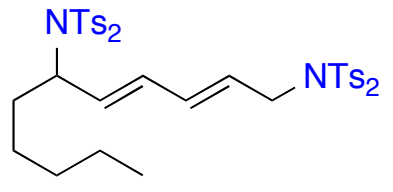

$22(60 \%)$

Scheme 9. Iodine(III)-promoted diamination of conjugated alkenes.

For the class of sterically more hindered alkenes $\mathbf{2 3}$ such as $\alpha$-methyl styrene 23a, allylic amination instead of diamination represents the preferred pathway. ${ }^{31}$ Thus, a large number of allylic amines $\mathbf{2 4}$ were generated from formal allylic $\mathrm{C}-\mathrm{H}$ amination (Scheme 10). Importantly, these reactions are best performed with a combination of mixed iodine(III) reagent 2 and bistosylimide. Reactions from PIDA usually provide lower yields, probably due to the higher concentration of acetic acid, which is detrimental to the stability of the products. As demonstrated for isotopically labeled $\alpha$-methyl styrene $\mathbf{2 3} \mathbf{a}-\mathbf{d}_{3}$, the reaction is in fact an oxidative amination within an allylic transposition. It proceeds through $\mathbf{H}$ via an initial alkene coordination to the electrophilic iodine(III) center. Deprotonation at the former allylic position initiates an $E_{2}$-process to the $\eta^{1}$-allylic iodine(III) $\mathbf{I}$, which undergoes nucleophilic substitution to the final allylic amination product 24a-d2. These steps are in agreement with isotope labeling experiments ${ }^{31}$ and computational investigation. ${ }^{27}$ The final step may also proceed through an allylic cation or through an $\mathrm{S}_{\mathrm{N}} 2$ ' reaction. The latter pathway is particularly interesting for preservation of the original double bond position. Examples include the cases of $\beta, \beta$-dimethylstyrene 25 and 2,5dimethyl-hexa-2,4-diene 27. For the latter, allylic mono- and diamination to $\mathbf{2 8}$ and $\mathbf{2 9}$, respectively, are available depending on the ratio between substrate and iodine(III) reagent. 


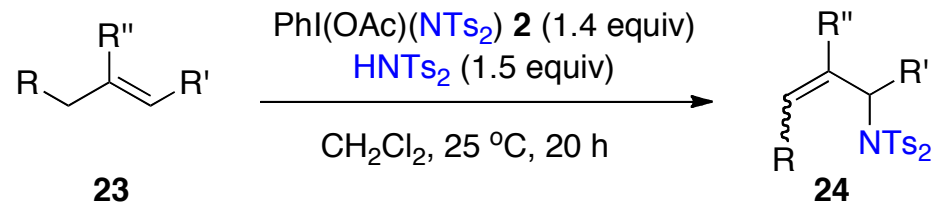

24 examples, 24-99\%

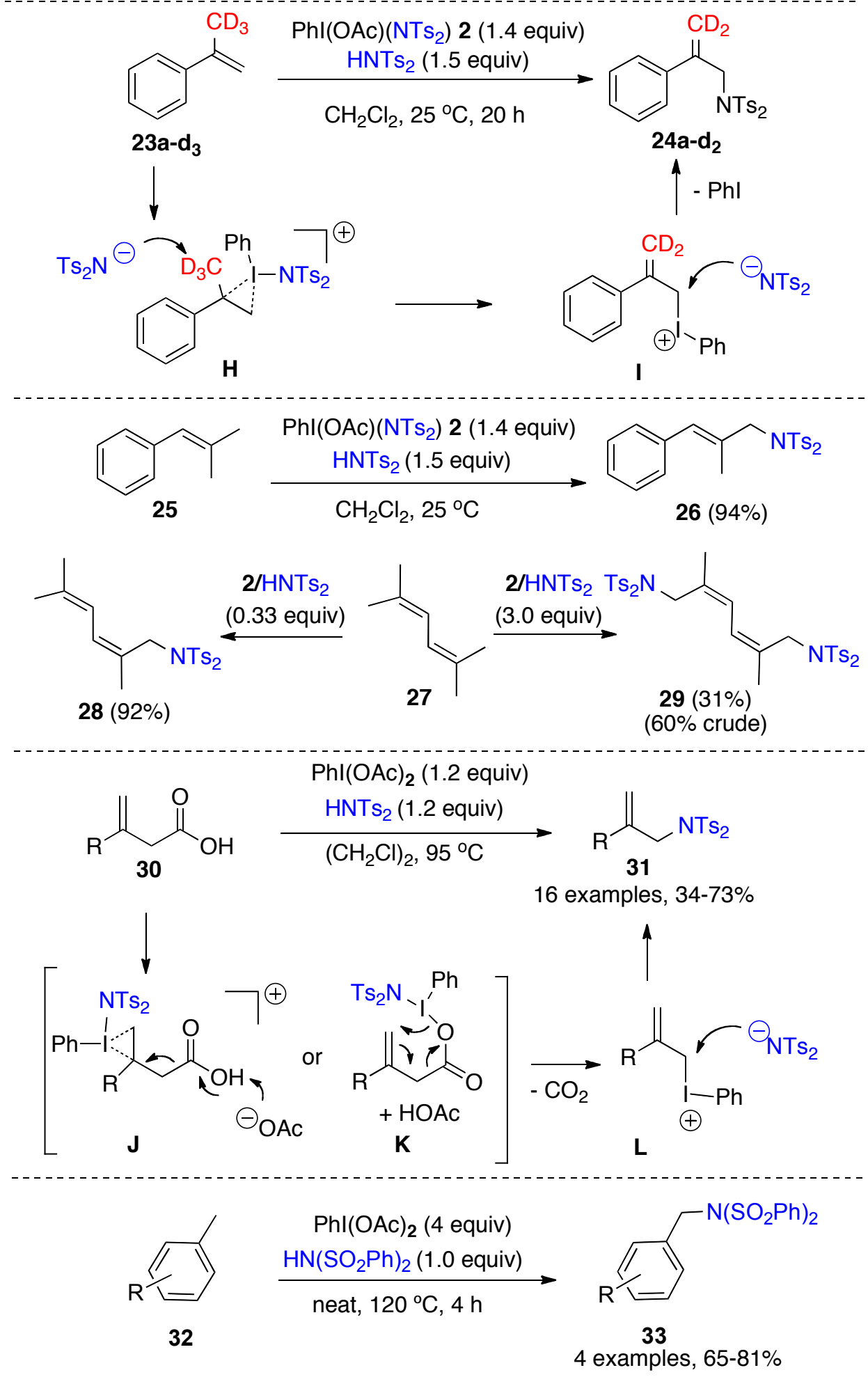


Scheme 10. Allylic amination through $\mathrm{C}-\mathrm{H}$ oxidation or oxidative decarboxylation and benzylic amination.

An alternative pathway to allylic amination was developed by Minakata. ${ }^{32}$ This transformation uses an oxidative decarboxylation on $\mathbf{3 0}$ followed by nucleophilic amination to 31. The active iodine(III) reagent $\mathbf{2}$ was formed in situ from PIDA and HNTs2. Following the mechanistic proposal for the related acetoxylation, $\mathbf{2}$ engages in an iodine(III)-promoted decarboxylation. This may either be a stepwise deprotonation, decarboxylation and opening of an iodonium(III) intermediate $\mathbf{J}$ or a concerted reaction from coordinated carboxylate to iodine(III) $\mathbf{K}$. The resulting intermediary allylic iodine(III) $\mathbf{L}$ can promote the final allylic amine derivative via an $\mathrm{S}_{\mathrm{N}} 2$ or $\mathrm{S}_{\mathrm{N}} 2$ ' amination or via previous iodine(III) release involving an allylic cation as discussed for related intermediate I. The reaction proceeds particularly well for aromatic substitution, but can also be conducted for aliphatic and acetylenylic substitution at higher reaction temperature. It was also successful for the related iodine(III) reagents derived from PIDA and saccharin and for preformed $\mathrm{PhI}(\mathrm{NPhth})_{2} 7$, which selectively provided the allylic amination products.

In addition, examples of benzylic amination of toluenes $\mathbf{3 2}$ were reported by Chang. Formation of the benzyl amines $\mathbf{3 3}$ was suggested to proceed through the corresponding radical and cationic intermediates derived from SET oxidation with PIDA. ${ }^{21}$

Electronically polarized alkenes are also effective substrates. For electron demanding alkene 34, standard diamination is not observed, but instead an unprecedented $\alpha$-amination of the carbonyl takes place (Scheme 11). ${ }^{15}$ The same outcome is obtained for acetophenone 36. These reactions are believed to proceed through the respective enol forms. This was confirmed by investigating the reaction for preformed enol ethers of acetophenones $\mathbf{3 8}$. As expected, the corresponding $\alpha$-aminated acetophenones $\mathbf{3 7}$ are formed within minutes at room temperature. Importantly, use of preformed reagent $\mathbf{4}$ is required for a high-yielding amination since it provides neutral conditions. The common $\mathrm{PhI}(\mathrm{OAc})_{2} / \mathrm{HNTs}_{2}$ reagent combination liberates acetic acid, which induces predominant cleavage of the TMS enol ethers and therefore slows down the reaction to a significant extent. The conditions can be equally well applied to cyclic enol ethers 39, which form the corresponding $\alpha$-aminated ketones $\mathbf{4 0}$ under very mild conditions. 
<smiles>CCCCOC=CC(C)=O</smiles>

34<smiles>CC(=O)c1ccccc1</smiles>

36
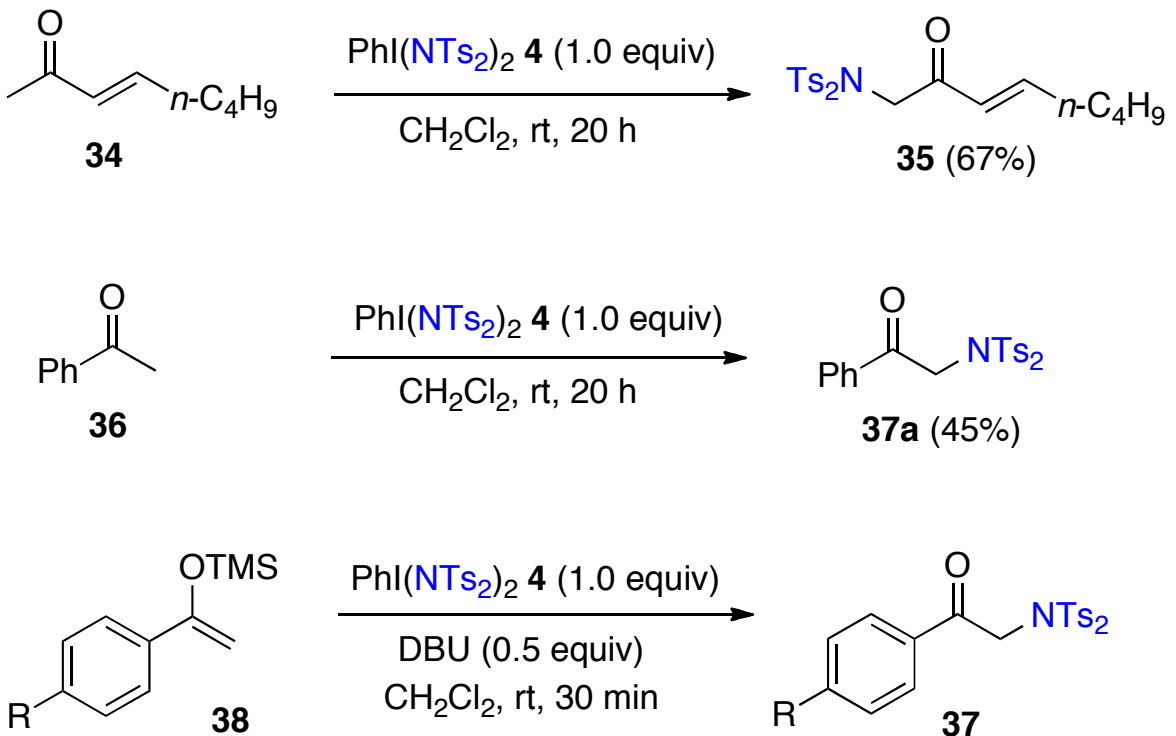<smiles></smiles>

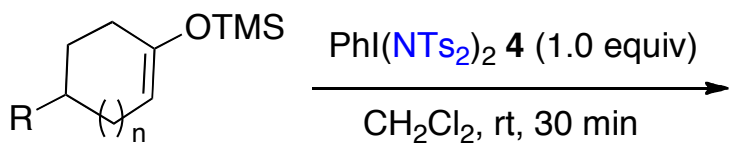

39<smiles>C=C([18OH])C(=O)O[Na]</smiles>

13 examples, $22-68 \%$

Scheme 11. The iodine(III)-mediated pathways to $\alpha$-aminated ketones.

This reaction was further investigated by Yoshimura and Zhdankin using a preformed dimeric $\mu$-oxo-bridged derivative $\mathbf{4 1}$ incorporating saccharine as the nitrogen source. ${ }^{33}$ Again, the reaction proceeds under neutral conditions and makes use of both iodine(III) units as oxidants. In some cases, the corresponding oxygenation from ambident behavior of the saccharine could be observed, however, amination to $\mathbf{4 2}$ usually constitutes the dominating pathway. Phthalimide requires a preformed benziodoxole reagent to provide related $\alpha$-aminated aminal products. ${ }^{23}$ 
Next, terminal acetylenes were investigated as unsaturated substrates for amination with bissulfonimides. ${ }^{34}$ Again, the preformed reagent 2 was required, since reagent formation from PIDA and free bistosylimide provided an increased amount of acetic acid by-product, which rapidly degraded the ynamide product. Under optimized conditions, a number of arylated acetylenes 43 were cleanly converted into the corresponding ynamides 44 in excellent yields (Scheme 12). The reaction was extended to the synthesis of an unprecedented ${ }^{15} \mathrm{~N}$-labeled derivative, thus demonstrating further synthetic value of the protocol. Based on physical-organic control experiments and literature precedence for other nucleophiles, ${ }^{35,36}$ the mechanism was proposed to involve an initial coordination $\mathbf{M}$ of iodine(III) to the acetylene followed by subsequent deprotonation through the acetate ligand. The resulting $\sigma$-acetylenyl iodine(III) $\mathbf{N}$ undergoes an aza-Michael addition of the bistosylimide under concomitant reductive loss of iodobenzene. The resulting alkylidene carbene $\mathbf{O}$ triggers a rearrangement to generate the final ynamide product. In addition, an enamide 46 together with its hydrolysis product acetylferrocene 47 was isolated from oxidation of acetylenyl ferrocene $\mathbf{4 5}$. This product stems from the reduced migration ability of ferrocene and is formed from the alkylidene carbene during aqueous work-up.

Aliphatic acetylenes $\mathbf{4 8}$ follow the same pathway via $\mathbf{P}$ and $\mathbf{Q}$ as for their arylated counterparts and generate the corresponding alkylidene carbene intermediates $\mathbf{R}$. Provided that the alkyl spacer is of correct length, insertion into an aliphatic $\mathrm{C}-\mathrm{H}$ bond becomes feasible and provides the corresponding cyclic enamide products 49. 


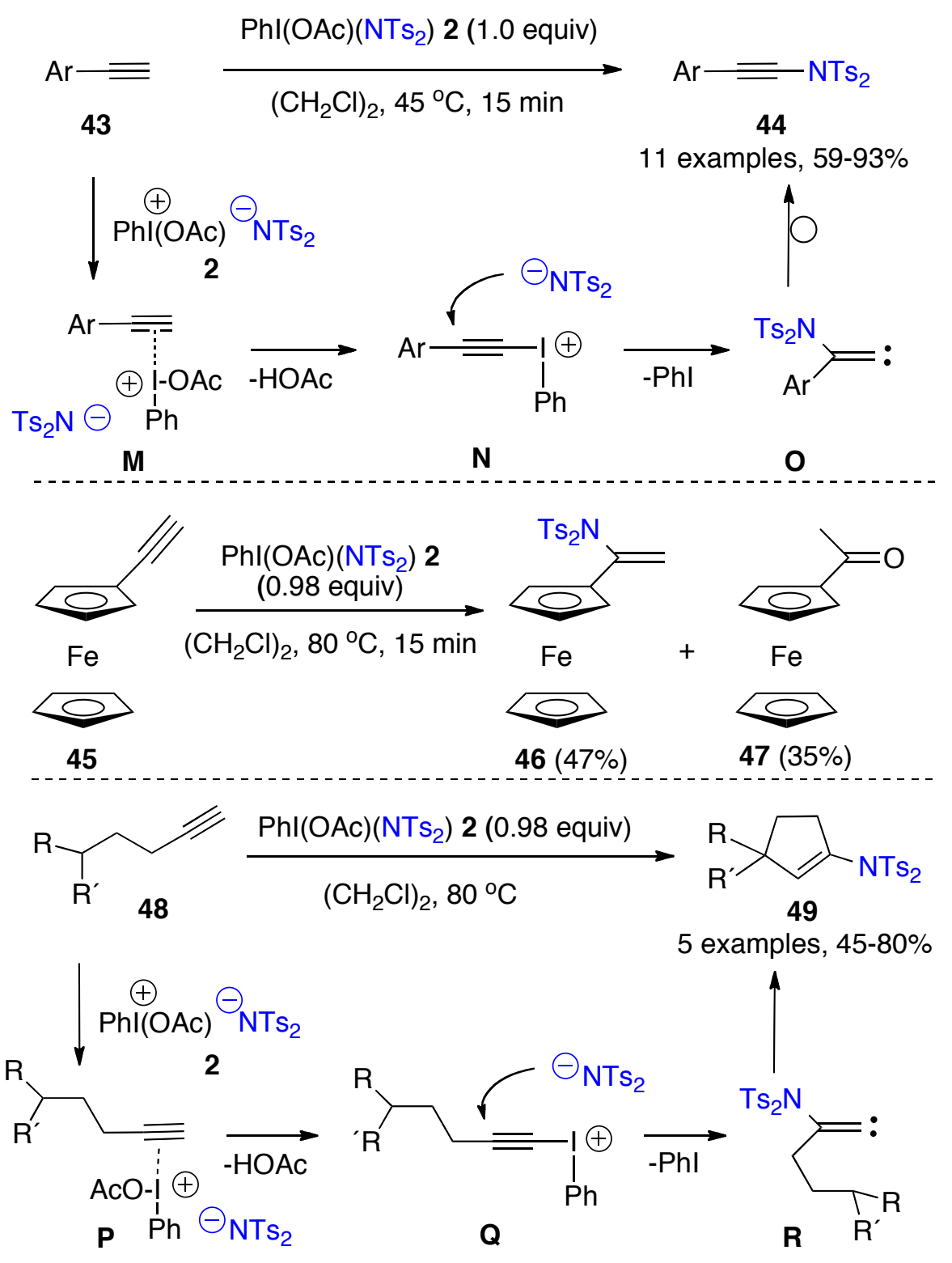

Scheme 12. Oxidative iodine(III)-promoted amination of acetylenes.

Finally, allenes were investigated as acetylene surrogates. ${ }^{37}$ Although allene oxygenation with iodine(III) has almost no precedence, the oxidative amination of allenes using defined iodine(III) reagent $\mathbf{4}$ is highly efficient (Scheme 13). The reaction proceeds readily for monosubstituted allenes $\mathbf{5 0}$ and leads to formation of the corresponding propargylic amines, either as the internal $\mathbf{5 1}$ or as the terminal isomer $\mathbf{5 2}$. This successful outcome derives from an initial interaction between the allene substrate $\mathbf{5 0}$ and $\mathbf{4}$, which directs the electrophilic iodine(III) to the 2-terminus of the allene and generates cationic intermediate $\mathbf{S}$. Subsequent nucleophilic addition to the benzylic position provides the amination intermediate $\mathbf{T}$, from which a reductive $\beta$-elimination generates the acetylene product $\mathbf{5 1}$. In contrast, a terminal amination reaction arrives at the regioisomeric intermediate $\mathbf{U}$, which engages in 
elimination to internal product 52. As experimentally observed, these two pathways are of related efficiency, unless specific electronic or steric influences favor one over the other. The regioselectivity can be influenced with $\mathrm{OPPh}_{3}$ as additive. $\mathrm{Ph}_{3} \mathrm{PO}$ coordination to the cationic fragment of $\mathbf{4}$ should generate species $\mathbf{4 - O P P h}$, in which the steric bulk of the phosphine oxide substituent disfavors the nucleophilic addition pathway to the terminal carbon thus providing a higher selectivity in favor of the terminal propargylic amines $\mathbf{5 1}$.

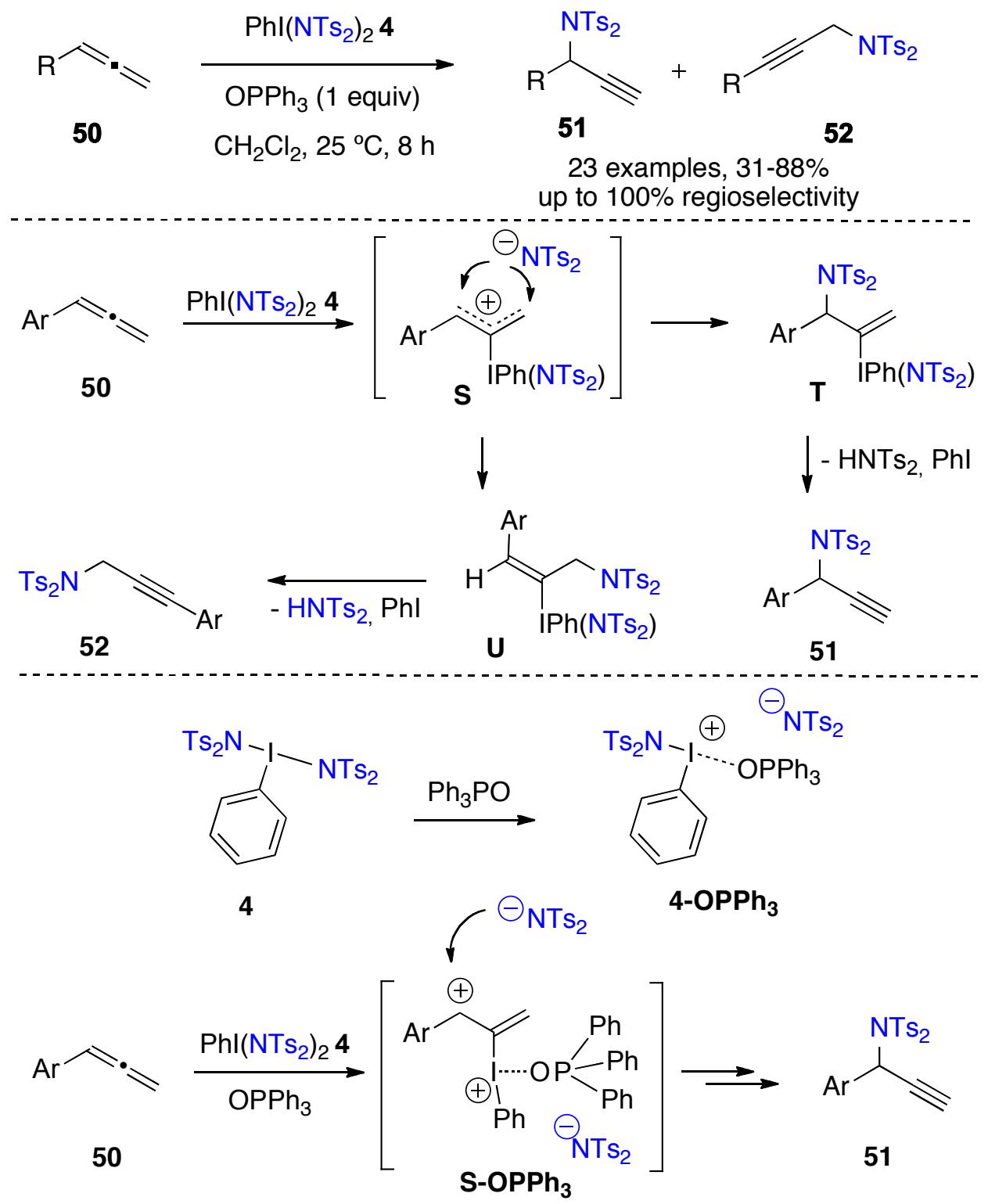

Scheme 13. Propargylic amines from iodine(III)-mediated amination of allenes.

Amination of arenes. For the particular case of substrate 53, the expected electrophilic cyclization to an indole derivative could not be accomplished (Scheme 14). ${ }^{15}$ Instead, a rare case of aromatic amination was accomplished (vide infra), which is assisted by the original aniline functionality. It is noteworthy that the resulting 1,4-diamine benzene $\mathbf{5 4}$ does not undergo any further oxidation to benzoquinone derivatives under the reaction conditions. 
This reaction was subsequently explored further. The group of Liégault and Taillefer reported the selective 4 -amination of anilides $\mathbf{5 5},{ }^{38}$ which uses lithium bistriflimide as the nitrogen source in combination with PIDA as the iodine(III). The authors provided evidence for an ionic adduct between LiNTf $_{2}$ and PIDA, which might not lead to ligand exchange at the iodine center. The reaction is proposed to follow ionic pathways starting from the classic interaction ${ }^{4,5}$ between the acetamide group and iodine(III) followed by subsequent nucleophilic amination of the arene and final rearomatization to 56. The same process can also be accomplished within a catalytic iodine(I/III) manifold starting from 4tolyl iodide with $m$ CPBA as terminal oxidant.

Zhu and $\mathrm{Xu}$ reported that within the same conceptual approach 8-amidoquinolines $\mathbf{5 7}$ can be selectively aminated at the 5-position. ${ }^{39}$ The authors suggest a mechanism that is based on an EDA complex and single electron transfer between the anilide and iodine(III). The resulting aniline radical cation undergoes regioselective amination from a preformed iodine(III) reagent followed by a second SET and deprotonation to provide the final 5aminated products 58. Alternatively, an ionic mechanism as discussed for $\mathbf{5 3}$ and $\mathbf{5 5}$ might be operating.<smiles>CC#Cc1ccccc1NC(=O)c1ccccc1</smiles>

53

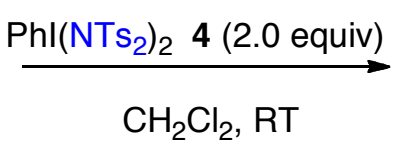

$\mathrm{CH}_{2} \mathrm{Cl}_{2}, \mathrm{RT}$

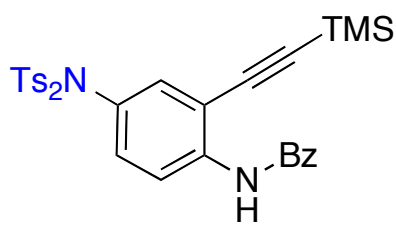

$54(80 \%)$<smiles>[R15]c1ccc(NC(C)=O)cc1</smiles>
$\mathrm{LiN}\left(\mathrm{SO}_{2} \mathrm{CF}_{3}\right)_{2}$ (1.2 equiv)

A: $\mathrm{Phl}(\mathrm{OAc})_{2}(1.2$ equiv), DCE, $20-50^{\circ} \mathrm{C}, 1.5 \mathrm{~h}$

B: $4-\mathrm{CH}_{3} \mathrm{C}_{6} \mathrm{H}_{4} \mathrm{l}$ (10 mol\%), $m$ CPBA (2.0 equiv), TFA (1.0 equiv)

DCE, $20^{\circ} \mathrm{C}, 4 \mathrm{~h}$<smiles>[R7]c1ccc(NC(C)=O)cc1NS(=O)(=O)OC(C)(C)C</smiles>

A: 14 examples, $30-81 \%$

B: 11 examples, 15-66\%<smiles>[R7]C(=O)Nc1cccc2cccnc12</smiles>
$\mathrm{HN}\left(\mathrm{SO}_{2} \mathrm{R}\right)_{2}$ ( 1.5 equiv) $\mathrm{Phl}(\mathrm{OAc})_{2}$ (2 equiv) $\left(\mathrm{CH}_{3}\right)_{2} \mathrm{O}, 25^{\circ} \mathrm{C}, 8 \mathrm{~h}$ $\left[\mathrm{R}=\mathrm{Ar}, \mathrm{CF}_{3}\right]$<smiles>[R7]c1cnc2c(NC(=O)P)ccc([N+](=O)[O-])c2c1</smiles>

20 examples, 64-84\%

Scheme 14. Iodine(III)-mediated aromatic C-H amination. 
The indole core represents another privileged arene with enhanced reactivity. This context was first explored for N-carbamoyl indoles, which undergo clean amination at the electrophilic C3-position (Scheme 15). This process can be combined with an iodinepromoted indole formation from 2-vinyl aniline 59, so that sequential two-fold amination to 60a is accomplished. ${ }^{40}$ Within one of the protocols, amination with iodosobenzene was demonstrated, thereby opening an additional way for amination with bissulfonimides.

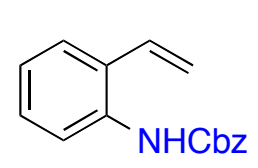

59

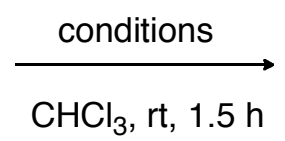

conditions

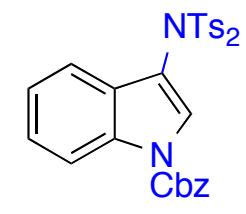

$60 a$

A: $\mathrm{ArSO}_{3} \mathrm{H}$ (1.1 equiv), $\mathrm{PhIO}$ (1.1 equiv), $\mathrm{Phl}\left(\mathrm{NTS}_{2}\right)_{2} 4$ (1.1 equiv):

B: $\mathrm{ArSO}_{3} \mathrm{H}$ (1.1 equiv), $\mathrm{PhIO}$ (2.2 equiv), $\mathrm{HNTS}_{2}$ (1.1 equiv):

Scheme 15. Iodine(III)-promoted sequential aminations.

Under less acidic conditions, stable iodine(III) derivatives can be formed. Moriyama and Togo treated $\mathrm{N}$-protected indoles $\mathbf{6 1}$ with PIDA and bissulfonimide to generate a series of stable mixed diaryliodonium derivatives $\mathbf{6 2}$ bearing bissulfonimide counterions, which were fully characterized including X-ray analyses (Scheme 16). ${ }^{41}$ The reaction also proceeds with other heterocycles (12 examples, 39-95\%). Importantly, the isolated compounds 62 do not undergo reductive $\mathrm{C}-\mathrm{N}$ bond formation unless they are heated in xylene at $150{ }^{\circ} \mathrm{C}$. This observation suggests that formation of 60a does not involve an intermediate 62. Further diversification can be accomplished by treatment of isolated compounds 62 with 1,3-dibromo-5,5-dimethylhydantoin 63, which induces a sequence of electrophilic bromonium formation $\mathbf{V}$ at the 2,3-indole bond, iminium cation formation $\mathbf{W}$ followed by nucleophilic 2-amination to $\mathbf{X}$ and elimination of the iodine(III) group to provide unique access to the corresponding 2-aminated,3-brominated building blocks $64 .{ }^{42}$ 
<smiles>c1ccc2[nH]ccc2c1</smiles>

61

$$
\begin{gathered}
\stackrel{\mathrm{HN}\left(\mathrm{SO}_{2} \mathrm{R}^{\prime \prime}\right)_{2}(1.2 \text { equiv })}{\mathrm{Arl}(\mathrm{OAc})_{2}(1.2 \text { equiv })} \\
\underset{\mathrm{CH}_{3} \mathrm{CN}, 40^{\circ} \mathrm{C}, 7 \mathrm{~h}}{\longrightarrow}
\end{gathered}
$$

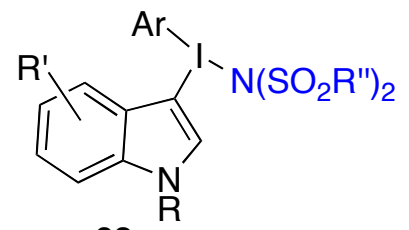

62

44 examples, $31-80 \%$<smiles>[R16][R6]OS(=O)(=O)c1c[nH]c2ccccc12</smiles>

60

8 examples, $20-78 \%$<smiles>O=S(=O)(O[Na])O[As]([Al])C1=C[R]2ccccc21</smiles>

62

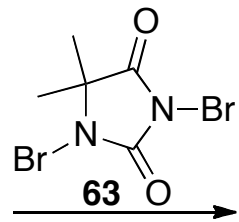

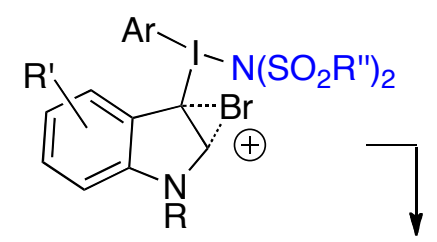

V

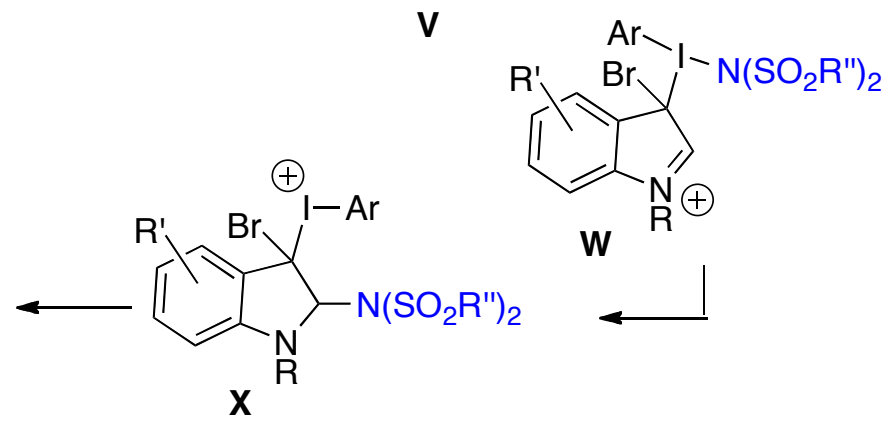

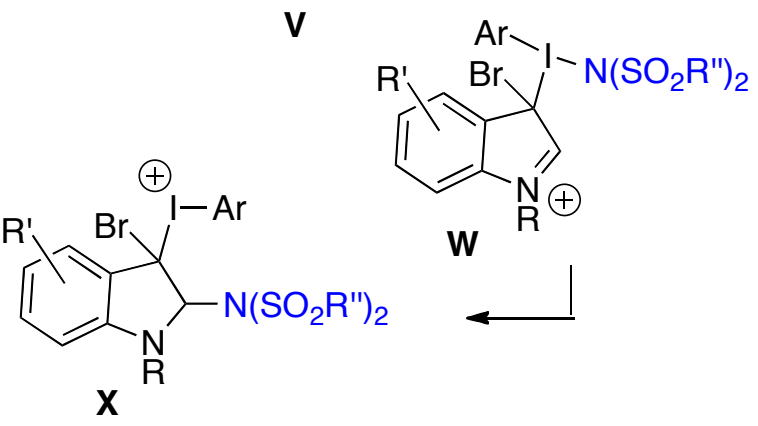

Scheme 16. Formation of (3-indolyl)iodine(III) derivatives and oxidative conversion.

For substrates $\mathbf{6 5}$ with a blocked 3-position at the indole core, amination takes place at the C2-position. ${ }^{43}$ This reaction was explored in detail for various indole and tryptamine derivatives. In the case of the latter, it is important to note that the potential intramolecular amination by the side chain amino group does not compete demonstrating once again the high intermolecular aminating power of the bisimido iodine(III) reagents (Scheme 17). The resulting 2-aminated tryptamine derivatives 66 can undergo a surprising number of chemoand site-selective transformations to provide entries into new 2-oxindole and 2-imidoindole derivatives 67 and 68 with quaternary benzylic centers. Thus, this approach opens new chemical space in indole derivatization. 


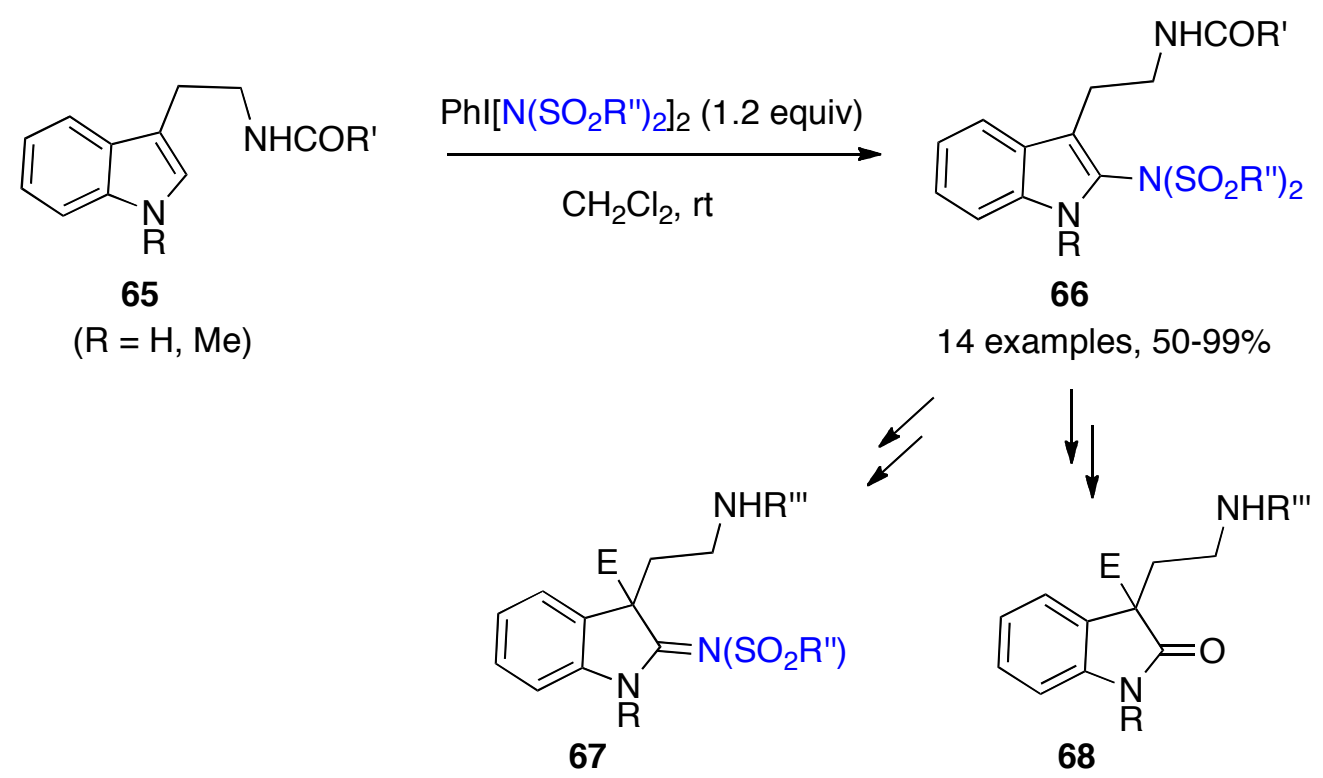

Scheme 17. Diversification of tryptamines based on C-2 amination.

In contrast to the discussed amination of electron-rich aromatic systems such as anilines and indoles, the direct amination reactions to provide $\mathrm{Csp}^{2}-\mathrm{N}$ bond formation on common arene cores are more challenging. Although bis(phenylsulfonyl)imide can aminate arenes under photochemical conditions, ${ }^{44}$ attempts towards reductive $\mathrm{C}-\mathrm{N}$ bond formation at iodine(III) did not provide the corresponding aniline derivatives. ${ }^{45}$ This context was studied for the bistosylimido diphenyl iodonium salt 69, which can be obtained through standard arylation at the acetoxy precursor $\mathbf{2}$ (Scheme 18). It did not show any C-N bond formation even at elevated temperatures. Instead, this compound served as a suitable precursor to the corresponding tetrafluorophthalimidato complex 70. Although the two X-ray analyses display related I-N bond lengths of 2.874(1) $\AA$ (69) and 2.758(2) $\AA$ (70), the reductive C-N bond formation through a $3 \mathrm{c} 4 \mathrm{e}$ pathway is influenced by electronic factors and only proceeds for the more electron-rich phthalimide derivative. This observation set the basis for the development of a selective amination of sterically congested aryliodonium salts to 2,6-disubstituted anilines. ${ }^{45}$ 


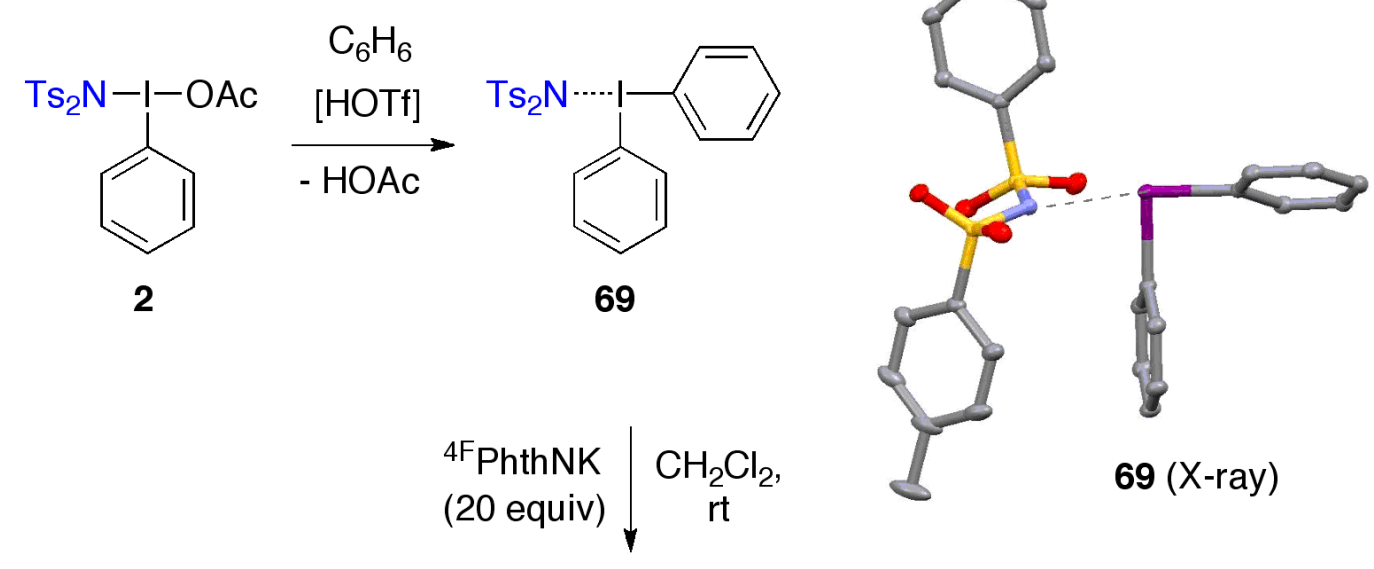

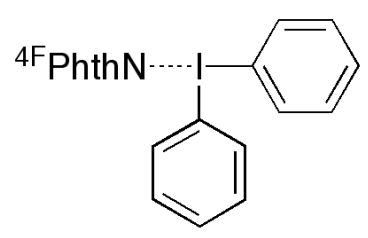

70

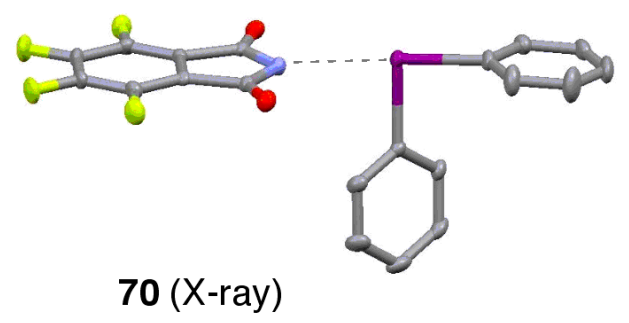

Scheme 18. Reductive aryl-nitrogen bond formation from diaryliodonium intermediates.

Enantioselective diamination of alkenes. The intermolecular diamination of alkenes by means of iodine(III) reagents has recently become the most successful approach in the field, particularly with respect to the elusive number of enantioselective transformations. Initially, we had screened several chiral candidates 72-74 and $\mathbf{7 6}$ that had been reported in literature. ${ }^{14}$ Reagents $\mathbf{7 2}$ and $\mathbf{7 3}$ containing elements of helical and axial chirality, respectively, provided selective diamination reactions of styrene (Scheme 19). However, the enantiomeric excesses of the products remained low $(14-32 \%$ ee $)$. A different outcome was obtained for aryl iodine (III) reagent $\mathbf{7 5}$ with chiral lactic side chains. This reagent exercised higher enantiocontrol. Bismesylimide provided a higher enantiomeric excess than bistosylimide (66 vs 50\% ee, respectively), which could be elevated to $85 \%$ for a reaction at $0{ }^{\circ} \mathrm{C} .{ }^{14}$ The active aminating reagents were prepared in situ by mixing the diacetoxyiodine(III) precursors with free bissulfonimides anticipating that a protonolysis event similar to the one for the achiral reagent 1 would take place. 


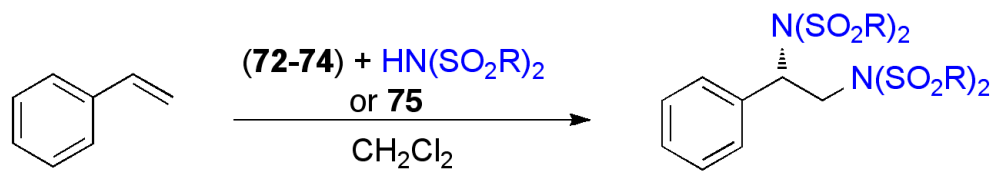

$8 b$
(S)-9b

$\left(\mathrm{R}=4-\mathrm{Tol}, \mathrm{CH}_{3}\right)$<smiles>CC(=O)O[IH]1(OC(C)=O)C[C@]23CCCc4cccc(c4-c4cccc1c42)C3</smiles>

$72+\mathrm{HN}\left(\mathrm{SO}_{2} \mathrm{R}\right)_{2}$<smiles>CC(=O)OI1OI(OC(C)=O)c2ccc3ccccc3c2-c2c1ccc1ccccc21</smiles>

73+ $\mathrm{HN}\left(\mathrm{SO}_{2} \mathrm{R}\right)_{2}$

$\mathbf{7 4}+\mathrm{HN}\left(\mathrm{SO}_{2} \mathrm{R}\right)_{2}$

75

$$
\begin{aligned}
& R=4 \text {-Tol: } 55 \% \text {, 32\% ee } \mathrm{R}=4 \text {-Tol: } 52 \%, 14 \% \text { ee } \quad \mathrm{R}=4 \text {-Tol: } 76 \%, 50 \% \text { ee } \quad \mathrm{R}=4-\mathrm{Tol}: 50 \%, 33 \% \text { ee } \\
& \mathrm{R}=\mathrm{CH}_{3}: 67 \%, 32 \% \text { ee } \mathrm{R}=\mathrm{CH}_{3}: 87 \%, 66 \% \text { ee }
\end{aligned}
$$

$\left(86 \%, 85 \%\right.$ ee at $\left.0{ }^{\circ} \mathrm{C}\right)$<smiles>COC(=O)C(C)Oc1ccccc1C(C)=O</smiles>

76

$2 \mathrm{HNTS}_{2}$ $\mathrm{C}_{6} \mathrm{H}_{5} \mathrm{Cl}, 55^{\circ} \mathrm{C}$

$\checkmark$<smiles>COC(=O)[C@H](C)Oc1ccccc1I([NH3+])[13CH2][13CH3]</smiles>

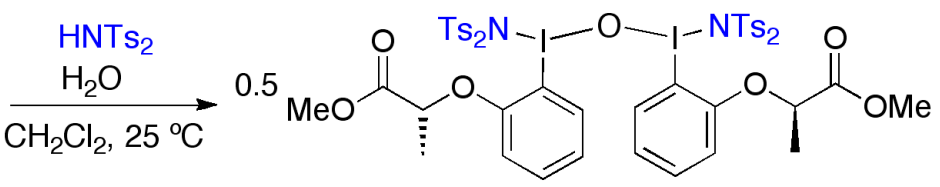

77

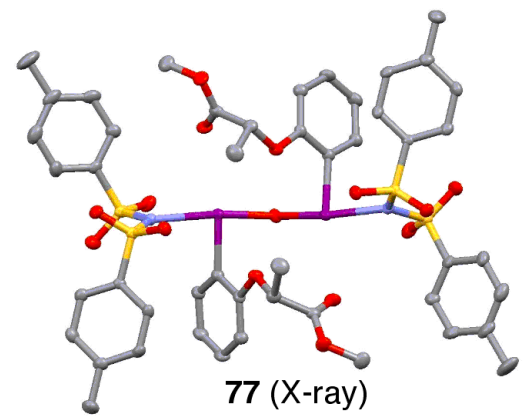

Scheme 19. Development of the enantioselective diamination of styrenes.

This context was probed for the chiral iodine(III) reagent 76 with a single lactate substituent. ${ }^{26}$ In this case, the sterically less hindered iodine(III) undergoes the anticipated formation of an iodine-nitrogen bond with bistosylimide leading to formation of the $\mu$-oxobridged dimer 77. Its treatment with a second equivalent of bistosylimide provided the bisimido iodine(III) species 75, which could also be accessed directly from 76. Isolated bisimido reagent $\mathbf{7 5}$ promotes diamination of styrene demonstrating the nature of the active reagents for enantioselective diamination to be the chiral bisimidoiodine(III) derivatives of the parent compound 4 . Due to the single chiral side chain, the enantioselectivity is lower (33\% ee) than for reactions with $\mathbf{7 4}$, but the conclusions on the nature of the structure of the active chiral iodine(III) reagent bearing I-N single bonds are secured by $\mathbf{7 5}$. Moreover, kinetic control experiments with 4-fluoro styrene 8a reveal that $\mathbf{7 5}$ promotes diamine formation to 9a within a half-time of only 8 minutes. Even if the product ee is of a low 
$24 \%$, the observed rate effect is important, which is attributed to the electronically favorable 2-oxygenated substituent as discussed for related achiral reagents 4-x (Scheme 4). With chiral bislactate $\mathbf{7 4}$, the enantioselective diamination displays a high scope. It comprises 2-, 3-, 4- and higher-substituted styrenes $\mathbf{8}$, which provide enantiomeric excesses of up to $95 \%$ (Scheme 20). Due to the four mesyl groups, all products could be crystallized to enantiopurity, usually within a single crystallization. The asymmetric diamination also proceeds for disubstituted alkenes such as $\beta$-methyl styrene $\mathbf{7 8}$ and indene $\mathbf{8 0 .}$

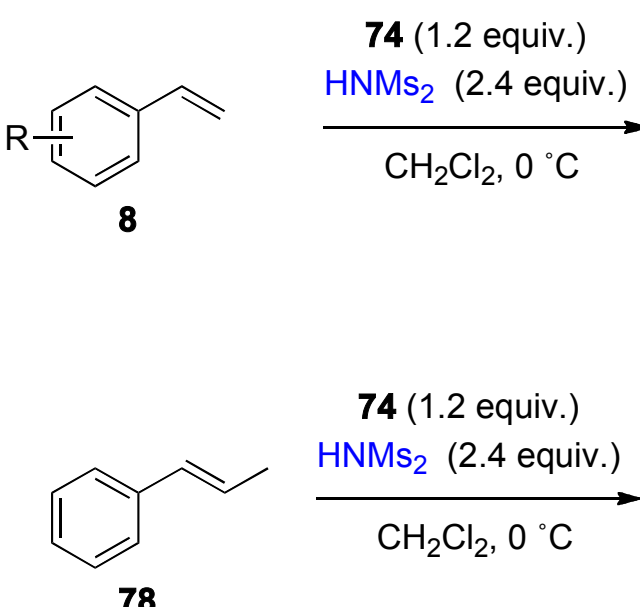

78

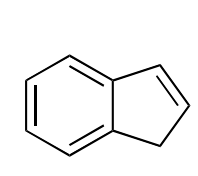

80

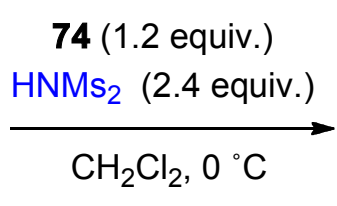

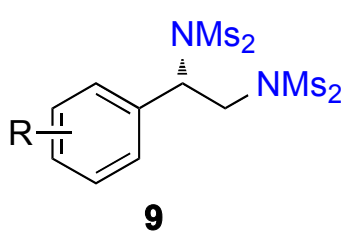

18 examples,

$44-75 \%, 74-95 \%$ ee

(<99\% ee after recryst.)

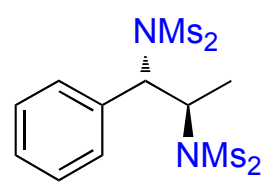

79

$87 \%, 90 \%$ ee

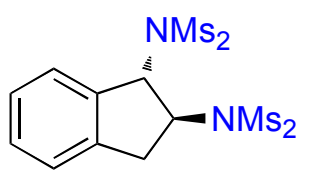

81

$66 \%, 63 \%$ ee

Scheme 20. First enantioselective intermolecular diamination of styrenes.

The effectiveness of this approach to the general class of 1-aryl ethylene diamines $\mathbf{8 3}$ was further demonstrated with its application to the synthesis of the alkaloid levamisole (Scheme 21). ${ }^{14}$ The required stereogenic center is derived exclusively from enantioselective diamination, which demonstrates that this novel synthetic methodology bears ample promise for asymmetric synthesis. 
<smiles>CN(C)CC(c1ccccc1)c1ccccc1</smiles>

$(S)-9 b$

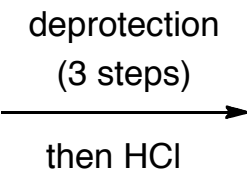

then $\mathrm{HCl}$<smiles>N[C@H](CCl)c1ccccc1</smiles>

82

(storage form)<smiles>NC[C@@H](N)c1ccccc1</smiles>

83

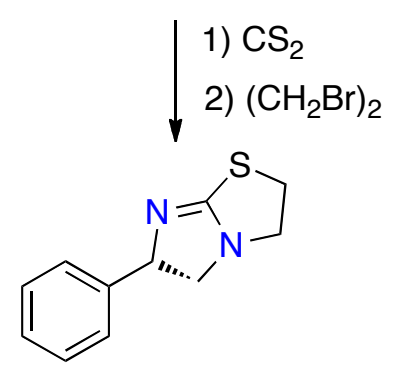

(S)-levamisole

Scheme 21. Enantioselective synthesis of levamisole from diamination of styrene.

Subsequent development of enantioselective diamination aimed to render the reaction catalytic in aryliodine. Following an extensive exploration of catalyst structure-reactivity relationship, ${ }^{46}$ an aryliodide bearing two chiral lactamide side chains 84 was identified as the optimum catalyst precursor. ${ }^{47}$ Suitable conditions for the desired iodine(I/III) redox catalysis employed 3-chloroperbenzoic acid ( $m \mathrm{CPBA}$ ) as terminal oxidant. In this way, enantiomeric excesses of up to $98 \%$ were obtained for terminal and internal styrenes (Scheme 22). It represents the proof of concept for enantioselective catalytic diamination of alkenes under intermolecular reaction control. Using isotopically labeled ${ }^{15} \mathrm{~N}-$ bismesylimide, the present reaction can also serve for the enantioselective synthesis of ${ }^{15} \mathrm{~N}-$ labeled diamines. For chiral substrates, the reaction proceeds under complete catalyst control as demonstrated for a vinyl steroid. 


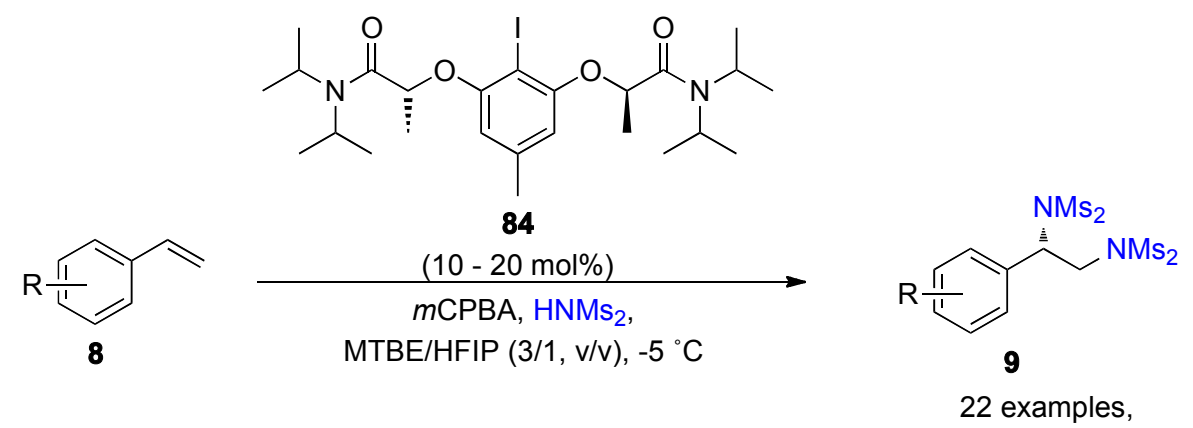

$54-87 \%$, 91-98\% ee
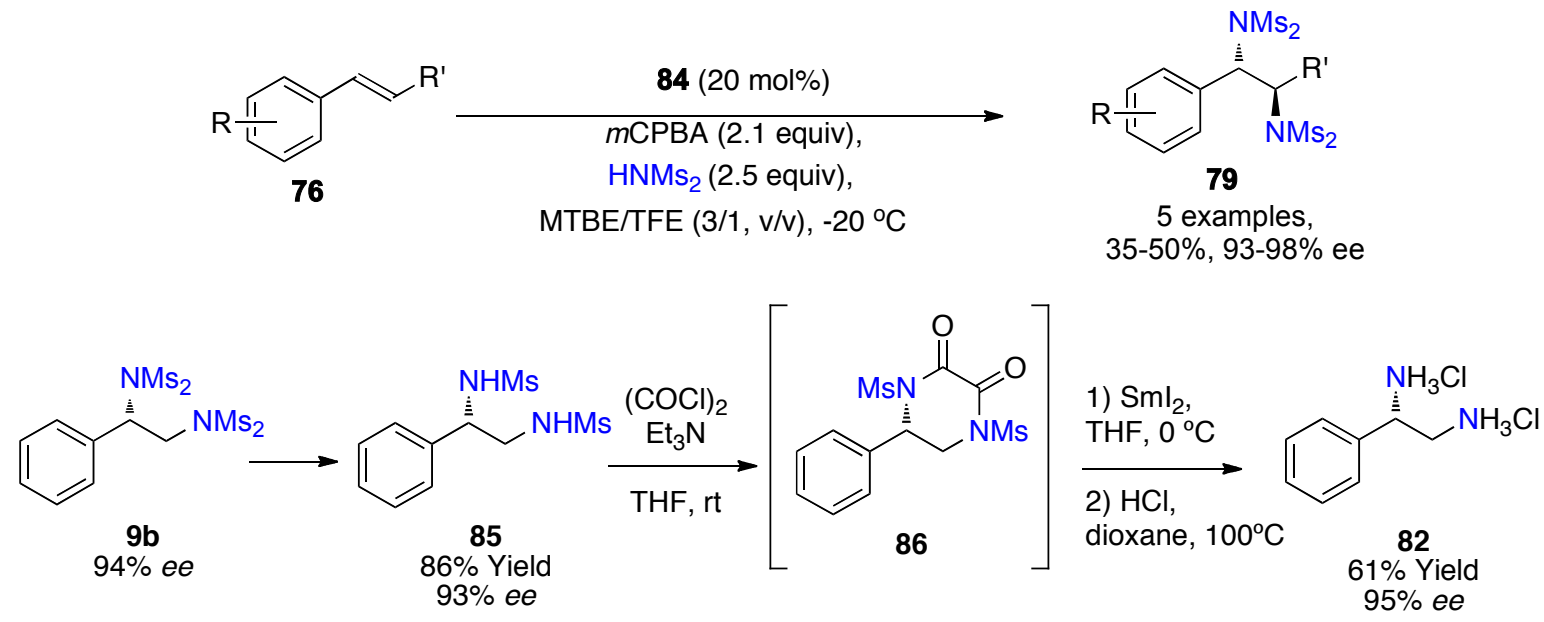

Scheme 22. Enantioselective iodine(I/III)-catalyzed diamination of styrenes.

An improved deprotection protocol established a sequence of demesylation to $\mathbf{8 5}$, formation of piperazine dione $\mathbf{8 6}$ and successive treatment with samarium diiodide and hydrogen chloride to generate the bisammonium chloride 82 without loss of ee. ${ }^{47}$ By this way, the pharmaceutically important 1-aryl ethylenediamine unit $\mathbf{8 3}$ is now available from enantioselective catalysis.

Regarding the mechanism, the dissociation capacity of the bismesylimide represents a crucial factor. At the stage of the active catalyst $\mathbf{Y}$, dissociation of one of the imido groups generates the required free site at the iodine center for efficient enantiotopic face differentiation within substrate coordination $\mathbf{Z}$. The obtained high enantioselectivity originates from direct amination at the benzylic position followed by intramolecular deiodination at stage $\mathbf{A A}$ to dioxooxathiazolidinium $\mathbf{A B}$, which adds bismesylimide to provide the final products as single diastereoisomers in excellent ee (Figure 2). 


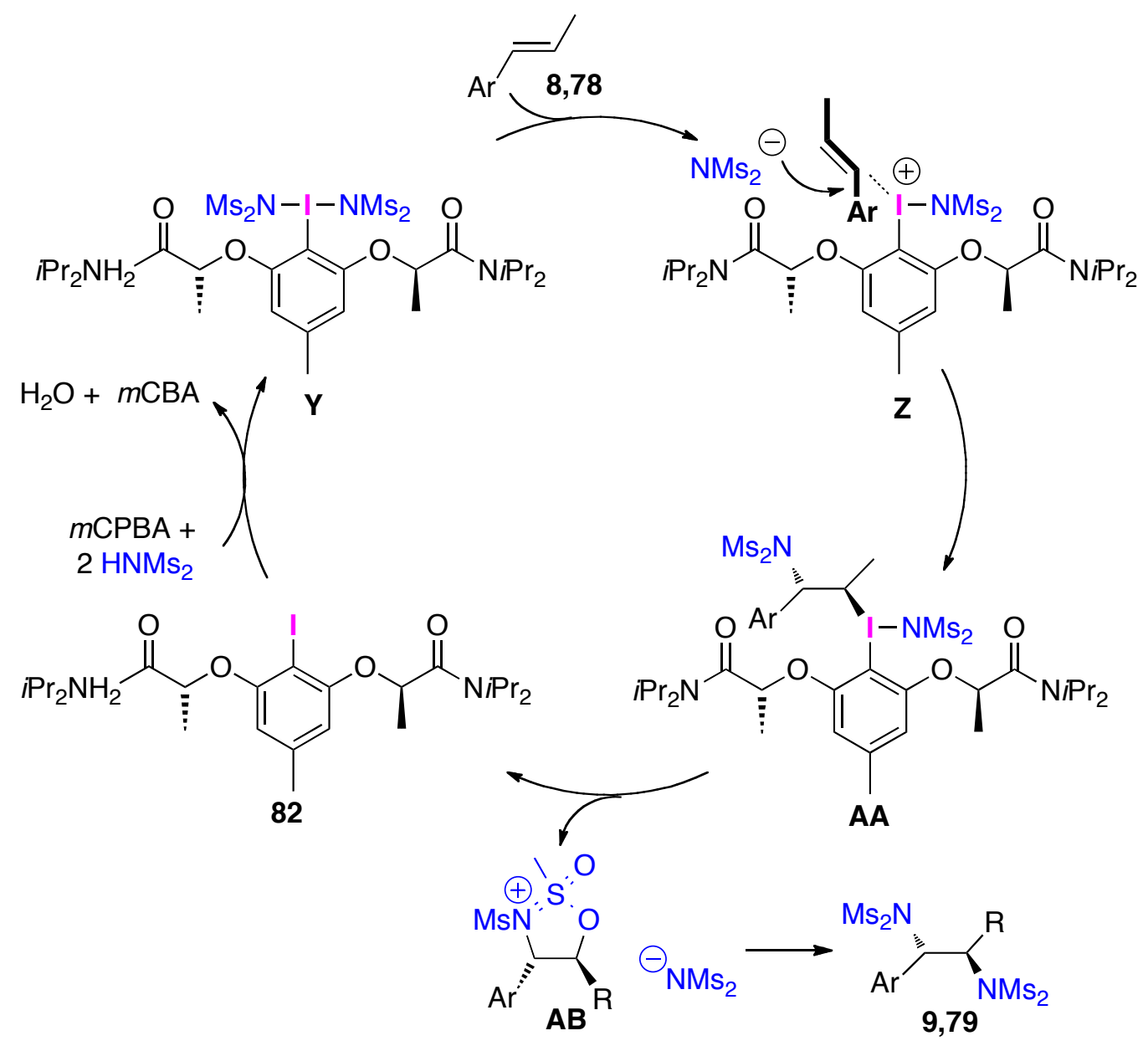

Figure 2. Mechanistic context of iodine(I/III)-catalyzed diamination of styrenes.

In summary, the development of a number of new iodine(III) reagents bearing defined iodine-nitrogen bonds has been devised for bissulfonimides. These reagents give rise to highly diverse reaction scenarios that are dominated by the electrophilic nature of the iodine(III) and the nucleophilic performance of the bissulfonimines. Successful reactions include the amination and diamination of unsaturated $\mathrm{C}-\mathrm{C}$ bonds, the amination of activated aromatic cores and enantioselective diamination of styrenes. The mechanistic basis for these oxidations is based on the specific reagent combination. While bissulfonimides provide a rich reactivity pattern including ambident nucleophilicity, the iodine(III) center displays reactivity that often resembles the behavior of transition metals in high oxidation state. For the future, one can expect the development of additional unprecedented reactions based on the exciting iodine(III)/bissulfonimide reagent system. 


\section{AUTHOR INFORMATION}

Corresponding Author

* E-mail for K.M.: kmuniz@iciq.es

\section{ORCID}

Kilian Muñiz: 0000-0002-8109-1762

Notes

The author declares no competing financial interest.

\section{Biographical Information}

Kilian Muñiz was born in 1970 in Hildesheim (Germany). He studied Chemistry at the Universities of Hannover (Germany) and Oviedo (Spain) and at Imperial College (UK) and earned his Doctorate in Organic Chemistry for work with Professor Bolm at RWTH Aachen (Germany) in 1998. He carried out postdoctoral research with Professor Noyori at Nagoya University (Japan), before starting his independent research at Bonn University (Germany) with Professor Dötz (2001-2005). From 2006 to 2009 he held a position as Full Professor at the University of Strasbourg (France), where he was also a member of the Institut Universitaire de France. He moved to ICIQ in Tarragona (Spain) as a group leader in 2009 and became ICREA Professor in 2010. His research interests include the development of new catalysts for general use in oxidative amination and diamination reactions of hydrocarbons.

\section{ACKNOWLEDGMENTS}

The author thanks all current and past co-workers for their experimental and intellectual contributions to this research project. Their names are provided in the references. The Ministerio de Economía y Competitividad is acknowledged for continuous financial support.

\section{References}

1 Zhdankin, V. V. Hypervalent Iodine Chemistry: Preparation, Structure, and Synthetic Applications of Polyvalent Iodine Compounds. Wiley, Chichester, 2013.

2 Hypervalent Iodine Chemistry (Wirth, T.; Ed.). Top. Curr. Chem. 373, Springer, 2016.

3 Yoshimura, A.; Zhdankin, V. V. Advances in Synthetic Applications of Hypervalent Iodine Compounds. Chem. Rev. 2016, 116, 3328-3435.

4 Tellitu, I.; Domínguez, E. The Apllication of [Bis(trifluoroacetoxy)iodo]benzene (PIFA) in the Synthesis of Nitrogen-Containing Heterocycles. Synlett 2011, 23, 2165-2175.

5 Tellitu, I.; Domínguez, E. Recent applications of the PIFA-assisted intramolecular olefin amidation reaction: An advantageous approach to the synthesis of nitrogen-containing heterocycles. Trends Heterocycl. Chem. 2011, 15, 23-32.

6 Ochiai, M.; Kaneaki, T.; Tada, N.; Miyamoto, K.; Chuman, H.; Shiro, M.; Hayashi, S.; Nakanishi, W. A. New Type of Imido Group Donor: Synthesis and Characterization of Sulfonylimino- $\lambda^{3}$-bromane that Acts as a Nitrenoid in the Aziridination of Olefins at Room Temperature under Metal-Free Conditions. J. Am. Chem. Soc. 2007, 129, 12938-12939. 
7 Ochiai, M.; Miyamoto, K.; Kaneaki, T.; Hayashi, S.; Nakanishi, W. Highly regioselective amination of unactivated alkanes by hypervalent sulfonylimino- $\lambda^{3}$-bromane. Science 2011, $332,448-451$.

8 Martínez, C.; Muñiz, K. Defined Palladium Phthalimidato Catalysts for Improved Oxidative Amination. Chem. Eur. J. 2016, 22, 7367-7370.

9 Martínez, C.; Muñiz, K., Palladium-Catalyzed Vicinal Difunctionalization of Internal Alkenes: A Diastereoselective Diamine Synthesis. Angew. Chem. Int. Ed. 2012, 51, 70317034.

10 Iglesias, Á.; Álvarez, R.; de Lera, Á. R.; Muñiz, K. Palladium Catalyzed Intermolecular $\mathrm{C}\left(\mathrm{Csp}^{3}\right)$-H-Amidation. Angew. Chem. Int. Ed. 2012, 51, 2225-2228.

11 Iglesias, Á.; Pérez, E. G.; Muñiz, K. An Intermolecular Palladium-Catalyzed Diamination of Unactivated Alkenes. Angew. Chem. Int. Ed. 2010, 49, 8109-8111.

12 Muñiz, K. High-Oxidation State Palladium Catalysis: New Reactivity for Organic Synthesis. Angew. Chem. Int. Ed. 2009, 48, 9412-9423.

13 Hickman, A. J.; Sanford, M. High-valent organometallic copper and palladium in catalysis. Nature 2012, 484, 177-185.

14 Röben, C.; Souto, J. A.; González, Y.; Lishchynskyi, A.; Muñiz, K. Enantioselective Metal-Free Diamination of Styrenes. Angew. Chem. Int. Ed. 2011, 50, 9478-9482.

15 Souto, J. A.; Martínez, C.; Velilla, I.; Muñiz, K. Defined Hypervalent Iodine(III) Reagents incorporating transferable Nitrogen Groups: Nucleophilic Amination through Electrophilic Activation. Angew. Chem. Int. Ed. 2013, 52, 1324-1328.

16 Willgerodt, C. Die Organischen Verbindungen mit Mehrwertigem Jod. Ferdinand Enke, Stuttgart 1914.

17 Hadjiarapoglou, L.; Spyroudis, S.; Varvoglis, A. Phenyliodine(III) Bis[phthalimidate]: A Novel Polyvalent Iodine Compound. Synthesis 1983, 207-208.

18 Papadopoulou, M.; Varvoglis, A. Phenyliodine(III) bisimidates, a novel class of trivalent iodine compounds. J. Chem. Res. 1983, 66-67.

19 Papadopoulou, M.; Varvoglis, A. The reaction of (disaccharinyliodo)benzene with ketones and active methylene compounds. J. Chem. Res. 1984, 166-167.

20 Wang, X.; Studer, A. Iodine(III) Reagents in Radical Chemistry. Acc. Chem. Res. 2017, $50,1712-1724$.

21 Kim, H. J.; Kim, J.; Cho, S. H.; Chang, S. Intermolecular oxidative C-N bond formation under metal-free conditions: control of chemoselectivity between aryl $\mathrm{sp}^{2}$ and benzylic $\mathrm{sp}^{3}$ C-H bond imidation. J. Am. Chem. Soc. 2011, 133, 16382-16385.

22 Kantak, A. A.; Potavathri, S.; Barham, R. A.; Romano, K. M.; de-Boef, B. Metal-Free Intermolecular Oxidative $\mathrm{C}-\mathrm{N}$ Bond Formation via Tandem $\mathrm{C}-\mathrm{H}$ and $\mathrm{N}-\mathrm{H}$ Bond Functionalization. J. Am. Chem. Soc. 2011, 133, 19960-19965.

23 Kiyokawa, K.; Kosaka, T.; Kojima, T.; Minakata, S. Synthesis and Structure of Hypervalent Iodine(III) Reagents Containing Phthalimidate and Application to Oxidative Amination Reactions. Angew. Chem. Int. Ed. 2015, 54, 13719-13723.

24 Romero, M.; Wöste, T.; Muñiz, K. Recent Progress in Vicinal Difunctionalization of Alkenes with Iodine(III) Reagents and Catalysts. Chem. Asian J. 2014, 9, 972-983.

25 Souto, J. A.; González. Y.; Iglesias, A.; Zian, D.; Lishchynskyi, A.; Muñiz, K. Iodine(III)-Promoted Intermolecular Diamination of Alkenes. Chem. Asian J. 2012, 7, 1103-1111.

26 Romero, R. M.; Souto, J. A.; Muñiz, K. Substitution Effects of Hypervalent Iodine(III) Reagents in the Diamination of Styrene. J. Org. Chem. 2016, 81, 6118-6122. 
27 I. Funes-Ardoiz, W. M. C. Sameera, R. M. Romero, C. Martínez, J. A. Souto, K. Muñiz, F. Maseras. DFT Rationalization of the Diverse Outcomes of the Iodine(III)-Mediated Oxidative Amination of Alkenes. Chem. Eur. J. 2016, 22, 7545-7553.

28 C. Röben, C.; Souto, J. A.; Escudero-Adán, E. C.; Muñiz, K. Oxidative Diamination Promoted by Dinuclear Iodine(III) Reagents. Org. Lett. 2013, 15, 1008-1011.

29 Lishchynskyi, A.; Muñiz, K. An Approach to Regioselective Diamination of Conjugated Dienes and Trienes. Chem. Eur. J. 2012, 18, 2212-2216.

30 Willstätter, R.; Waser, E. Über Cyclo-octatetraen. Ber. Dtsch. Chem. Ges. 1911, 44, 3423-3445.

31 Souto, J. A.; Zian, D.; Muñiz, K. Iodine(III)-Mediated Intermolecular Allylic Amination under Metal-Free Conditions. J. Am. Chem. Soc. 2012, 134, 7242-7245.

32 Kiyokawa, K.; Yahata, S.; Kojima, T.; Minakata, S. Hypervalent Iodine(III)-Mediated Oxidative Decarboxylation of Unsaturated Carboxylic Acids. Org. Lett. 2014, 16, 46464649 .

33 Yoshimura, A.; Koski, S. R.; Fuchs, J. M.; Saito, A.; Nemykin, V. N.; Zhdankin, V. V. Saccharine-Based $\mu$-Oxo Imidoiodane: A Readily Available and Highly Reactive Reagent for Electrophilic Amination. Chem. Eur. J. 2015, 21, 5328-5331.

34 Souto, J. A.; Becker, P.; Iglesias, Á.; Muñiz, K. Metal-Free Iodine(III)-Promoted Direct Intermolecular $\mathrm{C}-\mathrm{H}$ Amination Reactions of Acetylenes. J. Am. Chem. Soc. 2012, 134, 15505-15511.

35 Zhdankin, V. V.; Stang, P. J. Alkynyliodonium salts in organic synthesis. Tetrahedron 1998, 54, 10927-10966.

36 Ochiai, M.; Kunishima, M.; Nagao, Y.; Fuji, K.; Shiro, M.; Fujita, E. Tandem MichaelCarbene Insertion Reactions of Alkynyliodonium Salts. Extremely Efficient Cyclopentene Annulations. J. Am. Chem. Soc. 1986, 108, 8281-8283.

37 Purkait, N.; Okamura, S.; Souto, J. A.; Muñiz, K. Hypervalent Iodine Mediated Oxidative Amination of Allenes. Org. Lett. 2014, 16, 4750-4753.

38 Pialet, A.; Bergès, J.; Sabourin, A.; Vinck, R.; Liégault, B.; Taillefer, M. Iodine(III)Mediated para-Selective Direct Imidation of Anilides. Chem. Eur. J. 2015, 21, 1001410018.

39 Ji, D.; He, X.; Xu, Y.; Bian, Y.; Liu, W.; Zhu, Q.; Xu, Y. Metal-Free Remote C-H Bond Amidation of 8-Amidoquinolines on the C5 Position under Mild Conditions. Org. Lett. 2016, 18, 4478-4481; Org. Lett. 2016, 18, 5771-5771.

40 Fra, L.; Millán, A.; Souto, J. A.; Muñiz, K. Indole Synthesis Based On A Modified Koser Reagent. Angew. Chem. Int. Ed. 2014, 53, 7349-7353.

41 Ishida, K.; Togo, H.; Moriyama, K. Preparation of Heteroaromatic (Aryl)iodonium Imides as I-N Bond-Containing Hypervalent Iodine. Chem. Asian J. 2016, 11, 3583-3588. 42 Moriyama, K.; Ishida, K.; Togo, H. Regioselective Csp2-H dual functionalization of indoles using hypervalent iodine(III): bromo-amination via 1,3-migration of imides on indolyl(phenyl)iodonium imides. Chem. Commun. 2015, 51, 2273-2276.

43 Bosnidou, A. E.; Millán, A.; Cevallos, J.; Martínez, C.; Muñiz, K. Iodine(III)-Mediated Selective Intermolecular C-H Amination for the Chemical Diversification of Tryptamines. J. Org. Chem. 2016, 81, 6496-4504.

44 Ito, E.; Fukushima, T.; Kawakami, T.; Murakami, K.; Itami, K. Catalytic Dehydrogenative $\mathrm{C}-\mathrm{H}$ Imidation of Arenes Enabled by Photo-generated Hole Donation to Sulfonimide. Chem. 2017, 2, 383-392. 
45 Lucchetti, N.; Scalone, M.; Fantasia, S.; Muñiz, K. Sterically Congested 2,6Disubstituted Anilines from Direct C-N Bond Formation at Iodine(III). Angew. Chem. Int. Ed. 2016, 55, 13335-13339.

46 Haubenreisser, S.; Wöste, T. H.; Martínez, C.; Ishihara, K.; Muñiz, K. Structurally Defined Molecular Hypervalent Iodine Catalysts for Intermolecular Enantioselective Reactions. Angew. Chem. Int. Ed. 2016, 55, 413-417.

47 Muñiz, K.; Barreiro, L.; Romero, R. M.; Martínez, C. Catalytic Asymmetric Diamination of Styrenes. J. Am. Chem. Soc. 2017, 139, 4354-4357. 